\title{
A Survey of ICESat Coastal Altimetry Applications: Continental Coast, Open Ocean Island, and Inland River
}

\author{
Timothy J. Urban ${ }^{1, *}$, Bob E. Schutz ${ }^{1,2}$, and Amy L. Neuenschwander ${ }^{1,3}$ \\ ${ }^{1}$ Center for Space Research, The University of Texas at Austin, Austin, Texas, USA \\ ${ }^{2}$ Department of Aerospace Engineering and Engineering Mechanics, The University of Texas at Austin, Austin, Texas, USA \\ ${ }^{3}$ Department of Geography and the Environment, The University of Texas at Austin, Austin, Texas, USA
}

Received 15 November 2006, accepted 8 June 2007

\begin{abstract}
ICESat satellite laser altimetry provides an unprecedented set of global elevation measurements of the Earth, yielding great detail over ice, land and ocean surfaces. Coastal regions in particular, including seamless land-water transitions, benefit from the small footprint (50 to $90 \mathrm{~m}$ ), high resolution (40 Hz, 170 m along-track), and high precision (2 to $3 \mathrm{~cm}$ ) of ICESat. We discuss the performance and character of ICESat data in three example coastal scenarios: continental coast (Louisiana-Mississippi Gulf Coast, USA, including Lake Pontchartrain), open ocean island (Funafuti, Tuvalu), and an inland river (confluence of Tapajos and Amazon rivers, Brazil). Water elevations are compared to tide gauge heights and to TOPEX and Jason-1 radar altimetry. In demonstrating the utilization of ICESat, we also present examples of: laser waveform shapes over a variety of surface types (water, land, and vegetation); vegetation canopy heights (detecting large-scale destruction from Hurricane Katrina comparing data before and after); sub-canopy surface water; measurements of waves; and examination of along-stream river slope and comparisons of river stage to hydrologically-driven GRACE geoid change.
\end{abstract}

Key words: ICESat, Satellite altimetry, Laser altimetry, Waveform, Ocean, Island, Lake, River, Vegetation canopy, Tide gauge, TOPEX, Jason-1, GRACE

Citation: Urban, T. J., B. E. Schutz, and A. L. Neuenschwander, 2008: A survey of ICESat coastal altimetry applications: Continental coast, open ccean island, and inland river. Terr. Atmos. Ocean. Sci., 19, 1-19, doi: 10.3319/TAO.2008.19.1-2.1(SA)

\section{INTRODUCTION}

ICESat (Ice Cloud and land Elevation Satellite) was launched at 0045 UTC on 13 January 2003. The mission's primary goal is to detect elevation changes in the polar ice caps; secondary goals are to measure land elevation, gather vegetation canopy information, and measure distribution of clouds and aerosols (Zwally et al. 2002). Additional mission prospects have presented themselves in response to ICESat's successful performance over water surfaces: oceans, lakes, rivers, and wetlands (for example: Brown et al. 2004; Harding and Jasinski 2004; Schutz and Urban 2004; Lancaster et al. 2005; Padman and Fricker 2005; Urban and Schutz 2005; Calmant and Seyler 2006; Carabajal et al. 2006).

We discuss the performance and character of ICESat in three example coastal scenarios, using a variety of data samples spanning from February 2003 to June 2006. Section 1

\footnotetext{
* Corresponding author

E-mail:urban@csr.utexas.edu
}

provides a brief overview of the ICESat mission, including parameters and performances of the laser altimeter measurement system and derived data products. Section 2 examines ICESat across a complex continental coastline: the Louisiana-Mississippi Gulf Coast, USA. ICESat elevations (surface and vegetation) and waveforms are examined along a pair of ICESat tracks through the Mississippi Delta region nearest the landfall of Hurricane Katrina (29 August 2005). ICESat performance over water is investigated across Lake Pontchartrain, Louisiana, USA. Section 3 examines ICESat elevation near Funafuti, Tuvalu, an open ocean island. We compare ICESat data to radar altimetry and to tide gauge heights. ICESat elevation and waveform measurements are scrutinized across the island, including data crossing from the outer coast, to island ring, to central lagoon and back. Section 4 explores the confluence of the Tapajos and Amazon rivers, Brazil. We use ICESat to estimate river stage, river slope, and vegetation heights along the margins. River 
stage is compared to hydrologically driven geoid height change estimates from GRACE.

This investigation of coastal altimetry demonstrates ICESat performance in a variety of mission configurations (different lasers, spacecraft pointing angles, and extent of data calibration). Advantages and limitations of ICESat are discussed, including corroboration of the current high level of calibration, verification of the ICESat saturation correction, and the necessity for research into a calibrated cloud (forward scattering) correction. We show ICESat to be a valuable resource for application to a variety of geophysical and climatological studies.

\subsection{Spacecraft Hardware and Mission Scenario}

The Geoscience Laser Altimeter System (GLAS) is the sole payload of ICESat, comprised of three infrared lasers, a 1-meter diameter telescope, an instrument star tracker and other supporting equipment (see Zwally et al. 2002). Three lasers are operated sequentially over the projected mission lifetime (pre-launch scenario: 3 years planned with a 5 year goal). Each laser operates at $1064 \mathrm{~nm}$ (infrared) for surface elevation detection, and a frequency doubler creates a simultaneous $532 \mathrm{~nm}$ beam (visible green) to detect clouds and aerosols. During laser operations periods ("campaigns"), laser shots are fired continuously at $40 \mathrm{~Hz}$ over all surface types. The ICESat orbit is a retrograde frozen orbit at $94^{\circ}$ inclination and approximately $600-\mathrm{km}$ altitude. From this altitude, surface footprints are spaced $\sim 170 \mathrm{~m}$ apart; laser beam divergence (70 to $120 \mu \mathrm{rad}$ ) yields footprint diameters from 50 to $90 \mathrm{~m}$ (see Table 1). Pre-launch orbit configurations were to be an 8-day repeat orbit for calibration and validation, and then a 183-day repeat science orbit. A different science orbit has been implemented, as described below.

Two significant changes to the planned mission scenario took place after launch: first and foremost was the

Table 1. Mission parameters of 8 of the 11 ICESat data collection campaigns as of 2006. At the time of this analysis, campaign L3f has a preliminary near-real-time geolocation solution, as do the other campaigns not listed.

\begin{tabular}{|c|c|c|c|c|c|c|c|c|}
\hline Laser campaign $^{1}$ & L1a & $\mathbf{L} 2 \mathbf{a}$ & $\mathbf{L} 2 \mathbf{b}$ & L3a & L3b & L3d & L3e & L3f \\
\hline Year & 2003 & 2003 & 2004 & 2004 & 2005 & 2005 & 2006 & 2006 \\
\hline Season (N. Hemisphere) & Winter & Fall & Winter & Fall & Winter & Fall & Winter & Spring \\
\hline Start Date $(\mathrm{dd} / \mathrm{mm})$ & $20 / 02$ & $25 / 09$ & $17 / 02$ & $03 / 10$ & $17 / 02$ & $21 / 10$ & $22 / 02$ & $24 / 05$ \\
\hline End Date (dd/mm) & $21 / 03$ & $19 / 11$ & $21 / 03$ & $08 / 11$ & $24 / 03$ & $24 / 11$ & $28 / 03$ & $26 / 06$ \\
\hline Repeat Orbit (days) & 8 & 8,91 & 91 & 91 & 91 & 91 & 91 & 91 \\
\hline Initial energy $(\mathrm{mJ})^{2}$ & 72 & 80 & 57 & 67 & 68 & 43 & 38 & 32 \\
\hline Product Release Number ${ }^{3}$ & 218 & 428 & 428 & 428 & 428 & 428 & 428 & 128 \\
\hline 1- $\sigma$ PAD error $(\operatorname{arcsec})^{4}$ & 10 & 1.5 & 1.5 & 1.5 & 1.5 & 1.5 & 1.5 & 20 \\
\hline Footprint major axis $(\mathrm{m})^{2}$ & $\mathrm{NA}^{6}$ & 94 & 90 & 55 & $55^{7}$ & 52 & 52 & 51 \\
\hline Footprint eccentricity ${ }^{2}$ & $\mathrm{NA}^{6}$ & 0.9 & 0.8 & 0.6 & $0.6^{7}$ & 0.5 & 0.5 & 0.5 \\
\hline Ocean Bias $(\mathrm{cm})^{2,5}$ & -14 & -11 & -11 & -6 & -9 & -7 & -7 & -3 \\
\hline Ocean RMS $(\mathrm{cm})^{2,5}$ & 19 & 14 & 14 & 16 & 15 & 15 & 15 & 17 \\
\hline Figure color ${ }^{8}$ & Yellow & Blue & Orange & Grey & Red & $\mathrm{B} \& \mathrm{~W}$ & Green & Purple \\
\hline
\end{tabular}

${ }^{1}$ Laser data collection campaigns are abbreviated using the Laser number (L1, L2, and L3) plus a sequential letter in the order of acquisition.

${ }^{2}$ Adapted from The Attributes for ICESat Laser Operations Periods table (NSIDC, no date), produced by the ICESat Science Team.

${ }^{3}$ Product release numbers are a combination of calibration level (1 - 4) and software version (here 18 or 28). While older L1a data (Release 218) was released to NSIDC, subsequent campaigns were distributed only after reaching level 4 (Release 428) status.

${ }^{4}$ Fully-calibrated campaigns meet the 1.5 arcsecond 1 - $\sigma$ mission goal; worst-case errors for campaigns L1a and L3f are estimated from observed improvements to fully-calibrated campaigns (S. Bae and C. Webb, personal communication, 2006).

${ }^{5}$ Ocean bias and RMS are computed with respect to TOPEX (Urban and Schutz 2005).

${ }^{6}$ L1a has a bi-modal footprint whose size varies from 107 to $160 \mathrm{~m}$ depending on the date and calculation method used; precise definition is under evaluation (S. Bae, personal communication, 2006).

${ }^{7}$ Related to a change in laser energy, the L3b footprint size jumped to $85 \mathrm{~m}$ and eccentricity to 0.8 on 23 February 2005.

${ }^{8}$ Maps and elevation profiles of ICESat data throughout this paper consistently use these colors for individual campaigns. L3d data are black on light backgrounds, white on dark backgrounds. When combined per mission, ICESat tracks are blue, data from TOPEX and Jason-1 are pink, and data from the TOPEX interleaved orbit are tan. Please see the electronic version of this paper or contact the authors for color figures. 
failure of Laser 1 after 38 days of operation in the 8-day repeat orbit. Following the recommendations of a speciallyconvened review board, an adjusted mission scenario was adopted: a 91-day repeat orbit with an approximate 33-day subcycle. From this modified science orbit, ICESat has gathered 33 days of data three times per year (Schutz et al. 2005 ) in the same sub-cycle. This modified 33-day scenario has a repeat track spacing of $\sim 80 \mathrm{~km}$ at the equator and $\sim 20 \mathrm{~km}$ at $75^{\circ}$ latitude. Laser data collection campaigns occur during Northern Hemisphere winter (Feb/Mar), spring - summer (May/Jun), and fall (Oct/Nov) (see Table 1 for precise dates). This modified scenario extends the laser and mission life while providing sufficient data for intra-annual and inter-annual change detection (Schutz et al. 2005). Table 1 lists the eight laser campaigns considered for this study, which include data campaigns released publicly to the National Snow and Ice Data Center (NSIDC, no date) and one recent near-real-time data set temporarily only available to the ICESat Science Team (Laser 3f, spring - summer 2006) via the NASA Science Computing Facility (SCF, no date) at the time of this analysis. It is anticipated that fullycalibrated L3f data will be publicly available shortly after publication.

The second significant change to the mission operation was a processing adaptation designed to overcome problems with the innovative stellar reference system that was uniquely constructed for ICESat to yield measurements for precision pointing. Unlike pulse-limited radar altimetry, which is forgiving of small off-nadir pointing angles (Chelton et al. 2001), the geolocation of the GLAS laser footprints (Schutz 2002) is critically tied to both precision orbit determination (POD) (Rim and Schutz 2002) $(5 \mathrm{~cm}$ mission goal; $2 \mathrm{~cm}$ achieved) and precision attitude determination (PAD) (1.5 arcsecond 1- $\sigma$ mission goal; achieved a posteriori using instrument star tracker, gyros, and additional calibration corrections following an extensively-revised processing strategy (Bae and Schutz 2000; Luthcke et al. 2000; Bae and Schutz 2002; Luthcke et al. 2005; S. Bae, personal communication, 2006). Instrument and media (atmospheric transmission) corrections are also needed for ICESat, similar to or smaller than for radar; however, the PAD errors are the largest component of its single-shot error budget (Schutz 1998). Although referred to as attitude, PAD actually represents laser pointing, which includes spacecraft attitude and the precise determination of the GLAS laser position with respect to the spacecraft bus, which is not a fixed quantity. Table 1 lists the eight ICESat laser campaigns examined in this research, from the eleven data collection campaigns achieved from 2003 to 2006. The data from winter and fall campaigns are the easiest to post-process into fully-calibrated form because they are collected from a spacecraft orientation (sailboat mode, necessary for optimal solar panel alignment; see Schutz et al. 2005) having fewer PAD challenges (S. Bae, personal communication, 2006).
Campaigns from the other spacecraft orientation (airplane mode) are L1b (8 days total), L2c, L3c, and L3f, and they have not yet been fully calibrated. The fully-calibrated campaigns meet the 1.5 arcsecond (1- $\sigma$ PAD error) mission goal; worst-case errors for L1a and L3f shown in Table 1 are estimated from observed improvements of fully-calibrated campaigns (S. Bae and C. Webb, personal communication, 2006). All Laser 1 (L1) data were collected from the 8-day calibration orbit, but subsequent campaigns (following the first 8 days of L2a) are collected from the 91-day orbit. Although designed to be built to identical specifications and tolerances, the three GLAS lasers display significantly different characteristics [e.g., Table 1 of Magruder (2002) after Afzal and Dallas (2001)], including laser energy and decay rate (both affected/controlled by onboard temperature) and the footprint diameter and eccentricity. The ocean bias and RMS (root-mean-square about the mean) are computed with respect to TOPEX (Urban and Schutz 2005); larger negative numbers are obtained from campaigns having larger footprint size, suggesting a possible sea state bias-like effect for ICESat. Over calmer coastal waters, any sea state bias-like effect is diminished. The global ocean RMS is correlated with calibration level (1- $\sigma)$, and perhaps energy or footprint size, but as we will see, the noise level of individual tracks is much more dependent on surface and atmosphere characteristics. For plot consistency, each campaign is assigned a color for use in later figures; see Table 1 Note 8. Please view the electronic version of this paper or contact the authors for color figures.

The nominal pointing angle of ICESat is $5 \mathrm{mrad}\left(\sim 0.3^{\circ}\right)$ off-nadir, pitched upward in the direction of spacecraft motion, to avoid specular reflection of the laser pulse reflected to the telescope from flat, highly-reflective surfaces. The ICESat spacecraft has the flexibility to point toward any designated special target of opportunity (TOO) up to $5^{\circ}$ (or about $50 \mathrm{~km}$ ) off-nadir. Angles larger than nominal will reduce the probability of waveform saturation (see next section), but will increase the potential elevation error due to PAD error. Potential elevation errors $\left(\varepsilon_{h}\right)$ are related to laser incident angles $(\theta)$ and pointing knowledge errors $(\alpha)$ by:

$\varepsilon_{h}=K_{1} \theta \alpha$

where the constant $K_{1}=5 \mathrm{~cm} /{ }^{\circ} /$ arcsecond is derived geometrically from the altitude of the ICESat orbit $(600 \mathrm{~km}) . \theta$ is the laser beam incident angle with the ground (in degrees) and $\alpha$ is the pointing knowledge error in arcseconds. The incident angle $\theta$ is the sum of the off-nadir pointing angle and the ground slope. Over flat surfaces, such as water, the ground slope is effectively zero and $\theta$ can be regarded as the spacecraft off-nadir angle.

For example (recall Table 1), given a fully-calibrated campaign having $\alpha=1.5$ arcseconds (1- $\sigma)$ and a nominal 
pointing angle $\left(\theta=0.3^{\circ}\right)$, then $\varepsilon_{h}=2.25 \mathrm{~cm}$, which is the theoretical 1- $\sigma$ elevation error resulting from a 1- $\sigma$ PAD error; during off-nadir pointing to a TOO of $\theta=3.0^{\circ}, \varepsilon_{h}$ likewise scales by ten to $22.5 \mathrm{~cm}$. For campaigns presently having near-real-time calibration (e.g., L3f), $\varepsilon_{h}$ is $7.50 \mathrm{~cm}$ at nominal pointing $\left(\theta=0.3^{\circ}\right)$ and $75.0 \mathrm{~cm}$ during off-nadir pointing to a TOO of $\theta=3.0^{\circ}$. Since angle $\theta$ is a combination of pointing angle and ground slope, Eq. (1) illustrates that elevation errors are much larger over steep terrain even at nominal $\left(\theta=0.3^{\circ}\right)$ angles (e.g., the Trans-Antarctic Mountains).

Along with the elevation component of spot geolocation, the horizontal location is also affected by PAD errors. Potential spot location errors $\left(\varepsilon_{x}\right)$ are related to attitude errors $(\alpha)$ by:

$\varepsilon_{x}=K_{2} \alpha$

where the constant $K_{2}=2.9 \mathrm{~m} /$ arcsecond is derived geometrically from the altitude of the ICESat orbit $(600 \mathrm{~km})$ and can be considered independent of off-nadir angles $(\theta)$ for the small range of ICESat pointing angles (up to $5^{\circ}$ ). The horizontal position of each laser footprint of the fullycalibrated campaigns has a potential 1- $\sigma$ error of $\varepsilon_{x}=4 \mathrm{~m}$ due to 1- $\sigma$ PAD error, far smaller than the footprint diameter. On the other hand, the near-real-time PAD for L3f, for example, leads to $\varepsilon_{x}=58 \mathrm{~m}$, a number on the same order as the footprint size. Near-real-time data are therefore unsuitable for applications where a precise footprint location is necessary, such as verification studies requiring in situ data collection.

The equator crossing time of ICESat regresses about 1 hour during each 33-day laser campaign, and so the spacecraft can be considered nearly sun-synchronous over each campaign. As a consequence, a day-night elevation difference (ascending-descending or descending-ascending, depending upon the campaign orbit geometry) can be computed, which is non-zero but small [about $2 \pm 1 \mathrm{~cm}$ for global ocean averages from fully-calibrated campaigns (Urban and Schutz 2005)]. However, the individual coastal passes examined in this research can be expected to potentially experience larger variations, i.e., from -1 to $5 \mathrm{~cm}$ due to $3-\sigma$ thermal day/night effects, and possibly larger considering other effects. The spacecraft is subject to large (15 to 20 arcsecond) slow-moving thermally-driven variations in the instrument star tracker orientation with respect to the satellite bus, creating potential elevation uncertainties (day-night differences) of 22 to $30 \mathrm{~cm}$ [from Eq. (1) using $\theta=0.3^{\circ}$ ] and horizontal spot location uncertainties of 44 to $58 \mathrm{~m}$ [Eq. (2)] in the near-real-time processing of each laser campaign (e.g., L3f). These errors are both the reason for the extensive post-processing PAD procedures for ICESat and the reason why only data from fully-calibrated ICESat cam- paigns should be used where precise geolocation and submeter elevation precision is required. Fully-calibrated data have accounted for these variations, but near-real-time data should be used with considerable caution.

\subsection{ICESat Data}

The global GLAS Laser Altimetry (GLA) elevation data product is designated as product six (GLA06, Elevation). This GLA06 product provides the latitude, longitude, and elevation of the laser footprint, along with dozens of related parameters including elevation corrections, quality flags, and measured and modeled atmosphere information (WFF, no date). The digitized transmitted and received waveforms from each $40 \mathrm{~Hz}$ laser shot are recorded and are included in the first product generated (GLA01, Altimetry Data). GLA01 waveforms are digitized in $1 \mathrm{~ns}$ bin intervals, with 544 bins transmitted from each shot over land and ice and 200 bins over oceans and sea ice (Brenner et al. 2003). The GLA06 elevation is derived from a Gaussian fit of the maximum peak of each waveform, which may not correspond to the ground if vegetation is present, the ground is sloped, or discrete elevation levels lie within a single footprint. Access to parameters from alternate waveform-fitting procedures (to multiple peaks) is provided in the GLA14 product (Land/Canopy Elevation), which describes multiple (up to 6) peaks in the waveforms corresponding to distinct levels within the footprint. In general, the GLA06 elevation products provide adequate surface elevations for non-vegetated and smooth terrain surfaces. GLA01 and GLA06 are the products used in this analysis. When fully calibrated, the global ICESat elevations are estimated to have an absolute accuracy of 2 to $7 \mathrm{~cm}$ and a precision of 2 to $3 \mathrm{~cm}$ at $40 \mathrm{~Hz}$, tested over a variety of surfaces such as dry lakes and the Antarctic Dry Valleys (Fricker et al. 2005; Martin et al. 2005; Magruder et al. 2007).

There exist two important corrections for the ICESat laser elevations that are not typical of radar altimetry missions: the saturation correction and the atmospheric forward scattering correction. While the nominal pointing angle of ICESat is $5 \mathrm{mrad}\left(\sim 0.3^{\circ}\right)$ off-nadir to avoid secular reflection (see Section 1.1), a saturation phenomenon still occurs to some degree in all campaigns, with certain campaigns being more susceptible (namely L1a, L3a, and L3b). Saturation occurs when a number of $1 \mathrm{~ns}$ bins have amplitudes greater than some threshold function of gain (Brenner et al. 2003; Abshire et al. 2005). The returned energy oversaturates the detector, creating a saturated (clipped-peak) waveform (e.g., see several saturated waveforms in Fig. 16), which produces an incorrect elevation. The Precision Range Determination (PRD) working group of the ICESat Science Team has developed an analytical saturation correction for this effect, developed through lab testing of a ground laser and site-specific on-orbit validation tests using ICESat (Sun 
et al. 2005). A saturation correction is available on the data products and its application (additive to the elevation) is recommended for ice data (GLA12) for campaigns processed with software release 28 and higher (Release 128/428 elevation product release numbers; see Table 1). Over oceans, the saturation correction is not recommended in general, but on calm waters it can be beneficial, as will be shown.

The $532 \mathrm{~nm}$ (green) laser beam detects clouds and aerosols within the laser path, and when this green energy is sufficient (campaigns L2a and L2b), an additional media correction to compensate for forward scattering of the laser, called the estimated range delay (ERD), is provided at $1 \mathrm{~Hz}$ resolution (Palm et al. 2002). If clouds are optically too thick for the $1064 \mathrm{~nm}$ (infrared) beam, no surface elevation is obtained and only cloud information is measured. Validation and refinement of the ERD correction is in progress by the ICESat Science Team, and it is not yet recommended for Release 28 products. Therefore, no ERD correction has been applied to the data used in this analysis. The effects of clouds can still be considered in the present analysis. We will inspect the cloud flag ( 0 to 15 ) where available, which is given on the data product at $1 \mathrm{~Hz}$, based on a non-linear table of the optical depth: from 0 (optical depth $<0.010$ ) to 14 (optical depth $>2.000$ ), and where 15 denotes an invalid measurement.

ICESat data are also corrected for more traditional (from a radar point-of-view) media corrections (Herring and Quinn 1999). These include atmospheric delay (a $\sim 2.2 \mathrm{~m}$ dry troposphere correction at nadir) and a small (up to $\sim 3 \mathrm{~mm}$ ) wet troposphere correction based on the National Center for Environmental Prediction (NCEP) model. The ionosphere correction is negligible for laser wavelengths. Geophysical corrections applied to the Release 28 GLA elevation products include ocean tides (GOT99.2), ocean-loading tide, and solid Earth tide (Phillips et al. 1999). The small (less than $2 \mathrm{~cm}$ ) pole tide is not yet provided with the GLA data products, but is applied to the elevation data used for this research. An inverted barometer correction is not applied.

Note from Table 1 that Laser 2 (campaigns L2a and L2b) has a much larger and more elliptical footprint than Laser 3. The effects of footprint size, shape, and laser energy on elevation precision and accuracy are not fully characterized, but changes in footprint size and shape are observed to be temporally coupled to changes in energy (observed at SCF, no date), and these may be reflected in the bias estimates of the global mean sea level computations (Table 1) either through a changing sea state bias (Urban and Schutz 2005), instrument bias, or in some other unknown manner.

\section{CONTINENTAL COAST: LOUISIANA-MISSIS- SIPPI GULF COAST, USA}

The coastal areas of the Earth are home to nearly half the world's population, and the impacts of sea level rise (accompanied with tides, storm surges, erosion, and other effects) on coastal areas are an important future concern (e.g., IPCC 2001). In the United States, one of the most endangered coastal areas is along the Gulf of Mexico, which endures seasonal buffeting by hurricanes. Figure 1 shows the Mississippi River Delta region of the Gulf coastline, including partial coastlines of the states of Louisiana and Mississippi, overlaid with ICESat (blue) and TOPEX (pink, $\tan$ for the interleaved orbit) ground tracks. For ICESat, ground tracks represent the actual location of the laser spot impacting the surface, whereas radar altimetry assumes a nadir footprint location. ICESat tracks are continuous except where optically opaque clouds obscure the laser; radar altimetry excludes coastal and land areas without special processing and correction. When Hurricane Katrina made landfall on 29 August 2005 as a Category 3 storm near Bay Saint Louis, Mississippi (right green star, inside boxed area shown in Fig. 2), the results were devastating to this entire region, with much attention paid to the effects on the city of New Orleans, Louisiana (left green star). Along with the large human toll and unprecedented infrastructure damage costs (NOAA 2006), there are severe ecological costs, difficult to assess without measurements in advance of the storm. Satellite platforms, and ICESat in particular, can provide useful comparisons of Gulf Coast conditions before and after Katrina.

\subsection{Bay Saint Louis, Mississippi, USA}

Figure 2 shows a closer view of the ascending and descending ICESat ground tracks closest to the landfall of Hurricane Katrina near Bay Saint Louis, Mississippi (boxed region from Fig. 1). The overflight days for each pass are

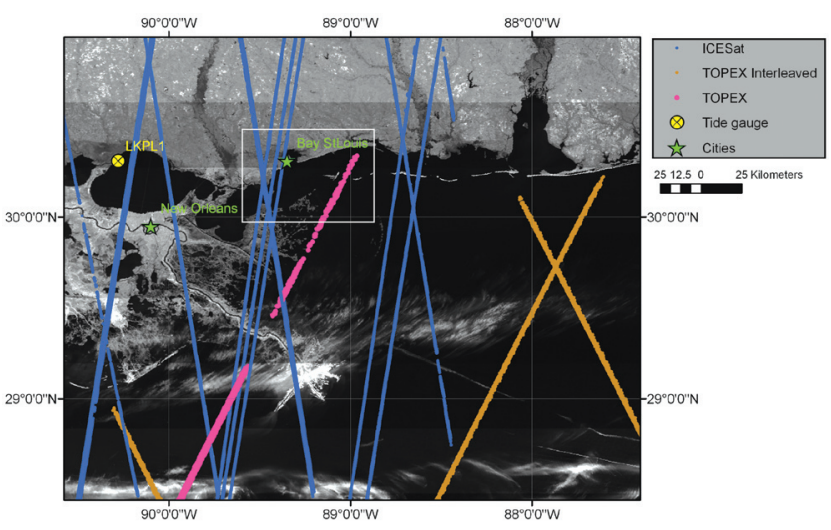

Fig. 1. MODIS image of the Mississippi River Delta region (7 Feb. 2006) with satellite ground tracks. ICESat tracks (blue) are from 5 single campaigns. TOPEX tracks (pink; tan for the later interleaved ground track) are each comprised of data from more than 100 repeat cycles. Note that the TOPEX data (unretracked) does not extend over land whereas ICESat is continuous except where its laser beam encounters optically opaque clouds. 


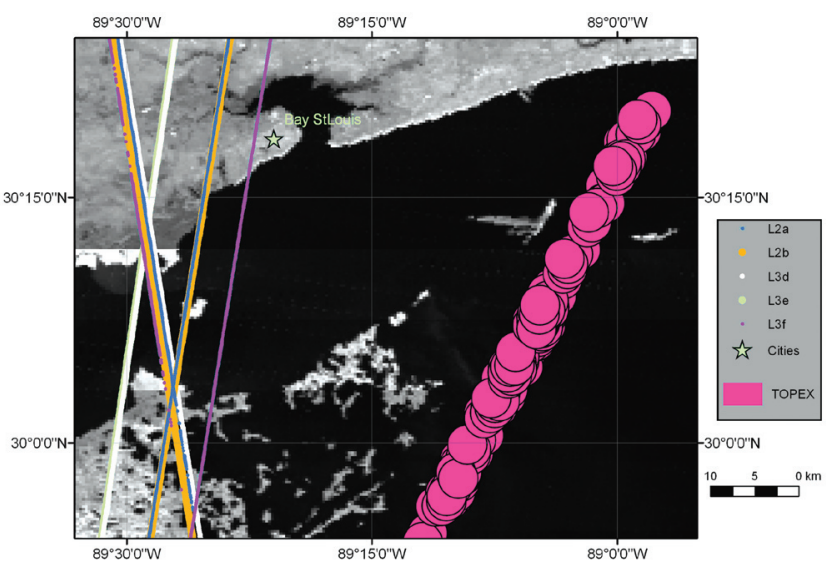

Fig. 2. ICESat ground tracks closest to the landfall of the eye of Hurricane Katrina near Bay St. Louis, Mississippi, USA. Ascending tracks from all five laser campaigns shown follow the same path very precisely, while descending tracks have significant cross-track separation

listed in Table 2. The map shows (from north to south) the Mississippi mainland coast, Mississippi Sound, and the northern extent of the Mississippi River Delta fan, Louisiana. For comparison, the closest available TOPEX radar altimeter footprint spots (pink) spanning more than 300 repeat cycles ( 8 years) are shown in the same region. TOPEX spots are illustrated as $5 \mathrm{~km}$ circles, roughly to scale (TOPEX footprints are typically 8 to $15 \mathrm{~km}$ ovals, depending on ocean wave height (Chelton et al. 2001), or smaller in calm waters). Note that the TOPEX footprints shown all occur over water, and would probably need to be corrected by a model wet troposphere correction, due to land contamination of the $20-40 \mathrm{~km}$ microwave radiometer footprints.

ICESat campaigns L2a and L2b occurred about 2 years before the hurricane, L3d tracks were sampled 2 months after the storm, and L3e and L3f were the next 2 subsequent campaigns, respectively 6 and 9 months after the hurricane (see Table 2). Ascending tracks from all 5 laser campaigns shown follow the same path within $\sim 1 \mathrm{~km}$ cross-track (Fig. 3a), about a quarter of the total potential cross-track separation. Cross-track distances from the reference orbit ground track in the mid-latitudes can be as high as $\pm 2 \mathrm{~km}$ due to the combination of (1) a $\pm 800 \mathrm{~m}$ orbit maintenance requirement, (2) the nominal $0.3^{\circ}$ pointing angle, and (3) a laser offset of $\sim 250$ arcseconds (compensated for during controlled pointing at TOOs and over the poles) (C. Webb, personal communication, 2006). Descending tracks have larger crosstrack separations (Fig. 3b): L2a (blue) and L2b (orange) are close to the reference track, the paths of L3d (black) and L3e (green) and are shifted $\sim 4$ to $6 \mathrm{~km}$ westward due to spacecraft roll in preparation for a TOO elsewhere on this same orbit (in Guatemala), and similarly L3f is shifted $\sim 4 \mathrm{~km}$ eastward due to spacecraft preparation for pointing at a TOO in northern Mississippi. This relatively large crosstrack variation creates three distinct crossover points (observed in Fig. 2). Small periodic variations in the distance plots are caused by the pointing control response to solar panel motion, a $1 \mathrm{~Hz}$ signal, which is correctly captured by the PAD procedure.

Figure 4 shows several key examples of the ICESat laser energy return waveforms along the ascending track of L2a. Each waveform plot is a record of the received energy $(\mathrm{V})$ as a function of time (ns). The transmit pulse (a) is virtually Gaussian. Simple surface types (b, c: water; d: land) return the laser energy back as nearly Gaussian reflections, with surface roughness (waves, wind effects, small-scale topography) tending to broaden the pulse. Plot (c) shows the narrowest returned waveform example, from calm coastal waters. The ocean waveform (b) is slightly wider due to larger wave effects further from the coast. Plot (d) shows significant pulse broadening due to surface characteristics. Strictly speaking, waveform (d) is not a simple single peak return (small secondary local maxima indicate complex topography), but the overall shape is approximated well with a single Gaussian. In addition to surface roughness, a larger relative surface slope (or laser incident angle) broadens the return waveform, indistinguishable from roughness broad-

Table 2. Mission parameters of 5 laser campaigns examined near Bay Saint Louis (BSL), Mississippi, USA.

\begin{tabular}{|c|c|c|c|c|c|}
\hline Laser campaign & $\mathbf{L} 2 \mathbf{a}$ & $\mathbf{L} 2 \mathbf{b}$ & L3d & L3e & L3f \\
\hline Year & 2003 & 2004 & 2005 & 2006 & 2006 \\
\hline Season (N. Hemisphere) & Fall & Winter & Fall & Winter & Spring \\
\hline Date over BSL asc (dd/mm) & $18 / 10$ & $18 / 02$ & $23 / 10$ & $23 / 02$ & $25 / 05$ \\
\hline Date over BSL des (dd/mm) & $06 / 11$ & $09 / 03$ & $11 / 11$ & $15 / 03$ & $14 / 06$ \\
\hline Average BSL vegetation Height ${ }^{1}$ asc $(\mathrm{m})$ & 11.4 & 6.7 & 5.5 & 3.2 & 5.4 \\
\hline Maximum BSL vegetation Height ${ }^{1}$ asc (m) & 26.1 & 26.0 & 17.4 & 6.8 & 14.0 \\
\hline
\end{tabular}

${ }^{l}$ Average of $0.1^{\circ}$ bins and maximum vegetation heights from 30.2 to $32.5^{\circ} \mathrm{N}$ from the ascending tracks (calculations as described in text). 
ening (Brenner et al. 2003), and so the broadening of (d) is most likely a reflection of both roughness and slope characteristics. When measuring truly flat terrain or water surfaces, shot-to-shot differences in ICESat waveform width can be considered as due to roughness alone. This analysis is implemented on the GLA06 elevation (maximum Gaussian peak; see Section 1.2), which is recognized to represent the ground elevation when flying over relatively flat, vegetation-free smooth surfaces such as ice and oceans. Multiple peaks are returned $(\mathrm{e}, \mathrm{f})$ from wherever a laser spot

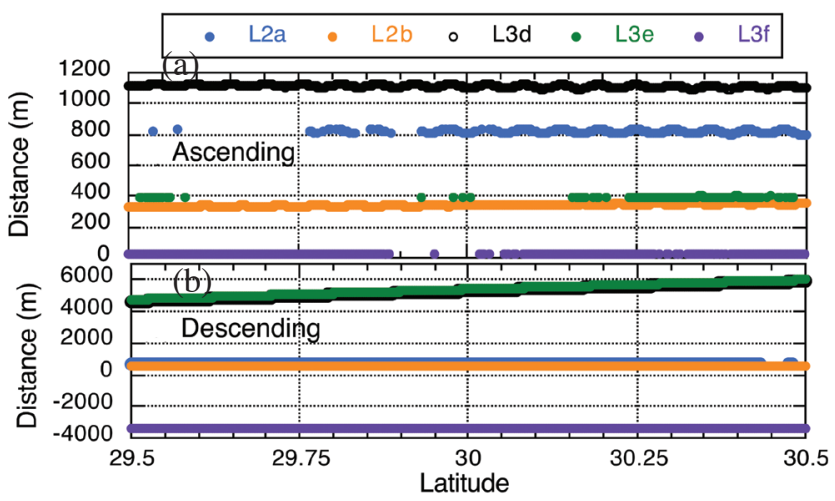

Fig. 3. ICESat ground track distance from the reference 91-day orbit, for the tracks shown in Fig. 2 for (a) ascending and (b) descending passes. encompasses a variable surface having large, discrete elevation levels within a single footprint, i.e., when encountering cliffs, buildings, and other structures or abrupt changes in topography, and in vegetated regions. In these cases, the maximum returned energy may not correspond to a ground reflection but rather to a higher elevation level, and thence the last peak of the waveform can be assumed to correspond with the lowest surface (ground level). In the presence of vegetation, the laser energy may penetrate through canopy gaps providing information about the intermediate vegetation structure as well as the upper canopy and underlying ground. By computing the time difference between the first reflection (upper canopy) and the last reflection (ground), an estimate of canopy height can be derived (Drake et al. 2002; Harding and Jasinski 2004; Harding and Carabajal 2005; Lefsky et al. 2005; Neuenschwander et al. 2006). This estimation procedure works best where the bare ground has relatively low relief. Based on comparisons to high-resolution DEMs (Harding and Carabajal 2005; Neuenschwander et al. 2006), two-peak (bi-modal) waveforms occur when the tree height is large compared to topographic relief, but vegetation can still influence the ground height estimates. Where topographic relief is a substantial fraction of canopy height, waveforms and their interpretation are more complicated (Harding and Carabajal 2005). (a)

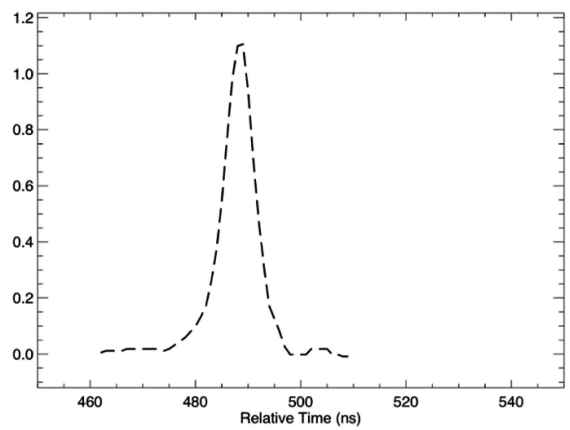

(d)

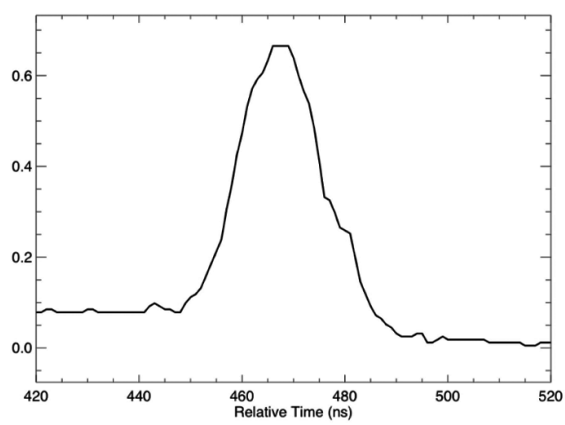

(b)

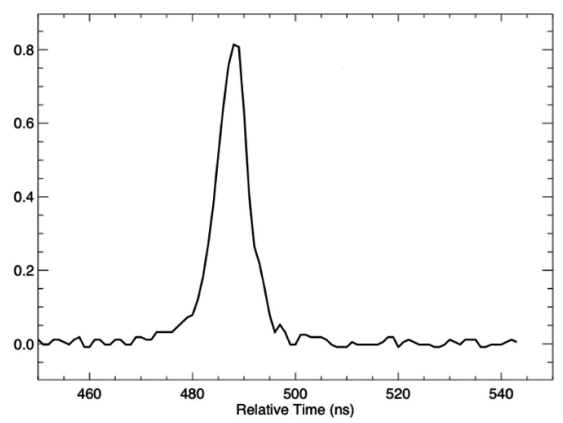

(e)

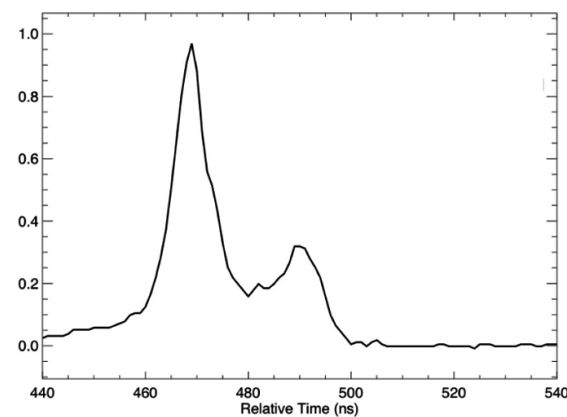

(c)

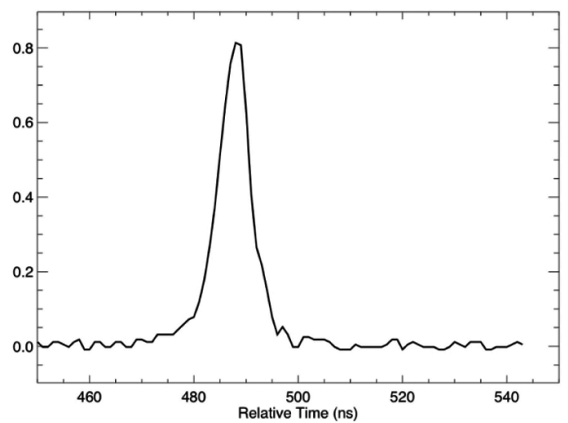

(f)

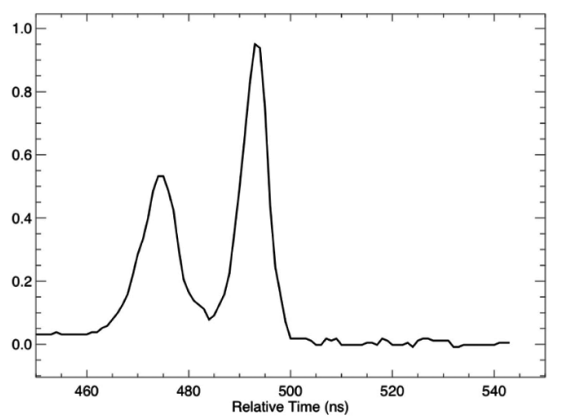

Fig. 4. ICESat laser return waveforms from campaign L2a. Abscissa is relative time in nanoseconds and ordinate is energy in volts. Examples include: (a) the transmit waveform, and returned waveforms from (b) open ocean, (c) calmer near-coastal water, (d) ground (rough), (e, f) areas with vegetation causing multiple (two main) peaks. In plot (e) the maximum (first, left) peak is the canopy and the second (right) peak is the ground. In plot (f) the maximum (second, right) peak corresponds to the ground while the first (left) peak is the canopy. 
Figure 5 shows the ICESat elevation profiles along the ascending (a) and descending (b) tracks of Fig. 2 with these plots extending further south to $28.5^{\circ} \mathrm{N}$. Because GLA06 elevations are maximum peak estimates, vegetation canopy is observed over the land (noisier) areas because of laser shots returning waveforms such as in Fig. 4e. In all of these plots the elevation data have been corrected for saturation effects; without this correction, calm coastal waters would yield incorrect measurements by as much as $\sim 1.5 \mathrm{~m}$ lower due to saturation. While it is difficult to assess the saturation correction over land without in situ verification, the benefit to coastal waters is apparent. A forward scattering effect is observed during the L3d ascending pass (grey) from about $28.5^{\circ}$ to $29.0^{\circ}$, causing decimeter-level noise due to light cloud cover (cloud flag 1 - 4). In general, the close-packed ascending tracks (a) clearly and consistently show the transition through coastal waters (from left to right): (1) coastal (open) ocean, characterized by relatively flat elevations modulated by tides $\left(28.5\right.$ to $\left.29.1^{\circ} \mathrm{N}\right)$, (2) the Mississippi River (29.1 to $29.2^{\circ} \mathrm{N}$ ), bordered by a brief sampling of land/vegetation, (3) an open water area (Breton Sound, 29.3 to $29.75^{\circ} \mathrm{N}$ ) between delta fans, and (4) the Mississippi Sound $\left(30.05\right.$ to $\left.30.2^{\circ} \mathrm{N}\right)$ following the land/vegetation area of the northern fan. Elevations increase dramatically on the mainland coastline (north of $30.25^{\circ} \mathrm{N}$ ) and are outside the range of this figure. The descending profiles (Fig. 5b) show similar features, although the lack of significant land/ vegetation in this area and the larger cross-track distances between the different laser campaigns tend to obscure the Mississippi River crossing (since it occurs at a slightly different latitude for each campaign); a noticeable jump in L3f (purple) at about $29.1^{\circ} \mathrm{N}$ marks its river crossing. The land/ vegetation north of the river is apparent in the descending passes, as are Breton Sound and Mississippi Sound. Water

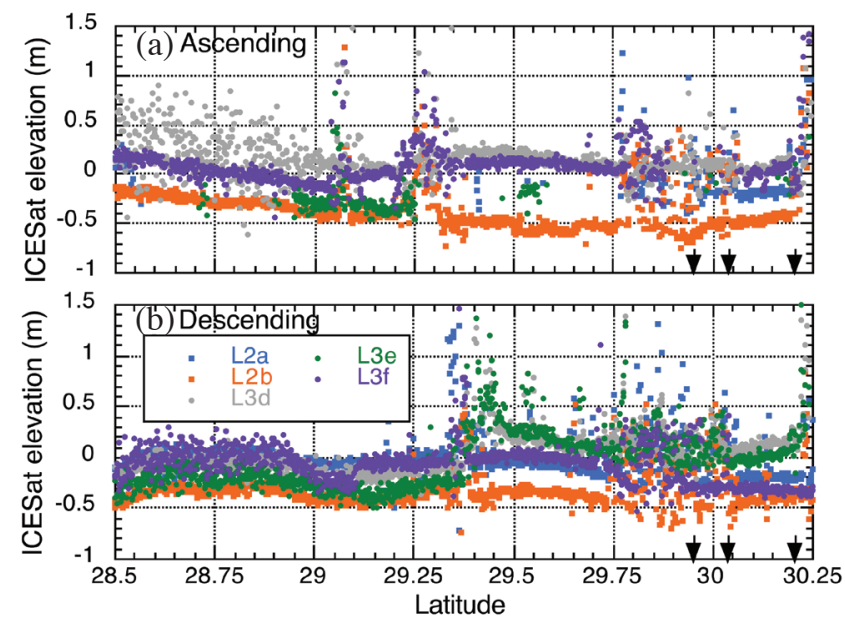

Fig. 5. ICESat elevations along the tracks shown in Fig. 2. Plot (a) shows the ascending tracks and (b) the descending. Crossover points are marked with arrows to indicate the three crossover intersection points. elevations depicted in Fig. 5 cannot be validated without a local tide gauge or accurate regional tide model, but the decimeter-level variations observed in the ICESat measurements probably represent true surface variations (weather effects and/or tide model error) given the sub-decimeter accuracy observed in other areas.

The ICESat-derived vegetation heights are estimated using a separation technique and are depicted in Fig. 6. For each ICESat waveform recorded, the total number of reflection sources (accounting for multiple peaks/elevations/ canopy levels) is identified numerically by counting the number of zero crossings of the first derivative of the energy profile above a threshold. Single peaks are assumed to correspond to surface reflections (ground or water). Multiple peaks are separated into a sum of Gaussian waveforms, where the maximum peak is assigned to either the first or last return. If the maximum peak is not the last peak temporally (on the far right as plotted), the maximum is assigned to the canopy height and the last peak is assumed to be the ground (Fig. 4e). When the maximum peak is the last peak (ground), the vegetation height is calculated from the point on the leading edge of the first peak where the 50\% energy level is reached (Fig. 4f). Figure 6 shows the vegetation height estimates above the surface (ground or water) for the five ICESat campaigns examined. Surface returns (single peaks) are depicted as identically zero and comprise about half of the measurements. Though rather busy, the plot does show $\sim 2$ to $7 \mathrm{~m}$ vegetation cover from 29.0 to $30.2^{\circ} \mathrm{N}$ for all campaigns, suggesting little change to the vegetation height structure of the southern landscape (damage not detectable). North of $30.2^{\circ} \mathrm{N}$, there are obvious differences between the measurements before Katrina (L2a and L2b) and after.

In order to better visualize and quantify these differences, the vegetation heights are collected into $0.1^{\circ}$ latitude bins $\left(0.1^{\circ}=\sim 11 \mathrm{~km}=\sim 1.5\right.$ seconds $=\sim 60$ spots $)$, plotted in Fig. 7. Heavy solid lines follow the average vegetation heights and thin dotted lines trace the maximum detected vegetation heights per $0.1^{\circ}$ bin. The L2a average (thick blue) and $\mathrm{L} 2 \mathrm{a}$ and $\mathrm{L} 2 \mathrm{~b}$ maximum lines (thin dotted blue and orange) are higher than all the others, indicating an 5-m drop in average vegetation heights, and an approximate 10- to 20-m drop in peak heights within that time interval, presumably due to hurricane damage. The maximum curve

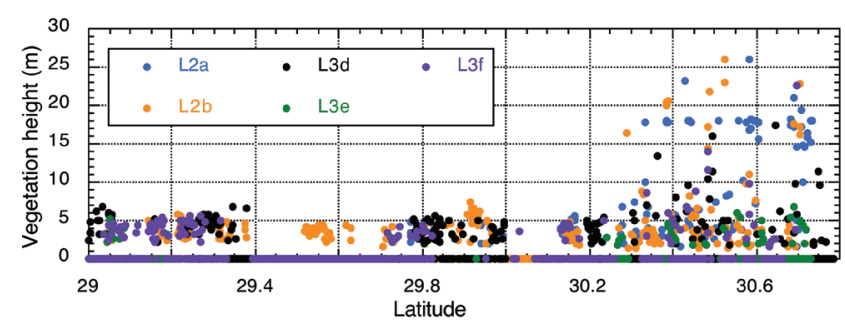

Fig. 6. Estimated vegetation heights north of $29^{\circ} \mathrm{N}$ along ascending tracks shown in Fig. 2. 


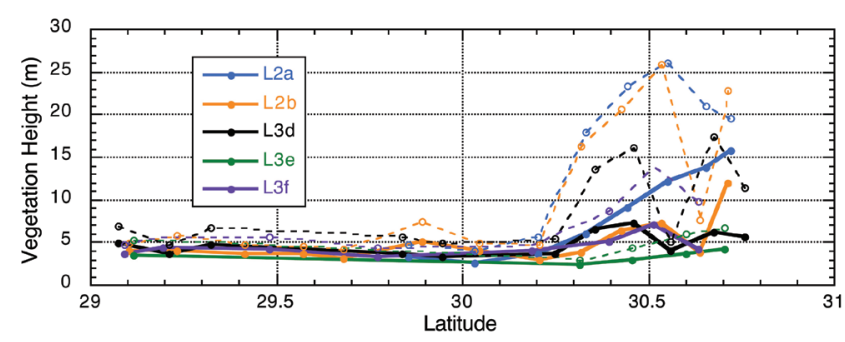

Fig. 7. Vegetation heights in $0.1^{\circ}$ bins along ascending tracks shown in Fig. 2. Heavy solid lines follow the average vegetation heights, thin dotted lines track the maximum detected vegetation heights. Campaigns L2a (blue) and L2b (orange) occurred before Hurricane Katrina (landfall 29 August 2005).

of L3d (black) indicates some higher vegetation than L2b and lower than later campaigns, which could be caused by cross-track separation sampling. Higher height measurements from L3d compared to L3e (green) and L3f (purple) could speculatively be caused by delayed hurricane effects, if a significant number of dead or damaged trees were cut down or fell over following the L3d data collection. Future research might correlate the precise ICESat spots with optical imagery or small-footprint airborne lidar (if available at the same times) to verify the elevations.

To obtain a single quantitative number for each pass, the vegetation height bins north of $30.2^{\circ} \mathrm{N}$ are themselves averaged, and the bin-averages and maxima are reported in Table 2. Overall, L2a shows the highest averages and maxima, followed by L2b. The differences in vegetation heights (before - after Hurricane Katrina landfall) span from 1 to $8 \mathrm{~m}$ for the bin average and from 11 to $20 \mathrm{~m}$ for maxima. These differences are significant, even allowing for sampling errors due to the cross-track separations between the tracks of the different campaigns. A future complete analysis should thoroughly examine independent sources of data (optical, lidar), additional ICESat campaigns, and would benefit from in situ data collection.

\subsection{Lake Pontchartrain, Louisiana, USA}

Next we compare ICESat measurements to tide gauge data from western Lake Pontchartrain, Louisiana, USA (Figs. 1 and 8) obtained from the Louisiana Universities Marine Consortium (LUMCON, no date). In general, radar altimetry displays a weaker correlation with near-coastal ocean tide gauges than with open-ocean gauges due to a combination of: (1) land contamination of both radar and radiometer measurements, causing a failure to properly "lock" onto small targets; (2) models derived from radar (e.g., tides), which are less accurate in coastal regions due to the aforementioned land contamination problem; and (3) local water level affected by the interactions between local weather, bathymetry and topography. ICESat seamlessly measures across land-water surface transitions, and is exempt from concern (1), but will be affected by (2) to the extent that the global (radar-derived) tide models employed are in error, and by the unknown effects of (3). One area in which ICESat can provide potential assistance is in the improvement of coastal tides globally, as has already been demonstrated around Antarctica (Padman and Fricker 2005).

The Lake Pontchartrain tide gauge (LKPL1) is lcated along the northwestern edge of the lake at $30.31^{\circ} \mathrm{N}, 269.72^{\circ} \mathrm{E}$ (Fig. 8). Here we examine the descending tracks closest to the tide gauge. Four of the campaign tracks lie very close together, within $\sim 400 \mathrm{~m}$ of each other (see Fig. 9); the geolocation of L3f places its descending track $\sim 1 \mathrm{~km}$ to the east of the others due to a distant TOO on the same track. Lake levels across the lake are shown in Fig. 10. Saturation corrections are applied to all elevations, although only

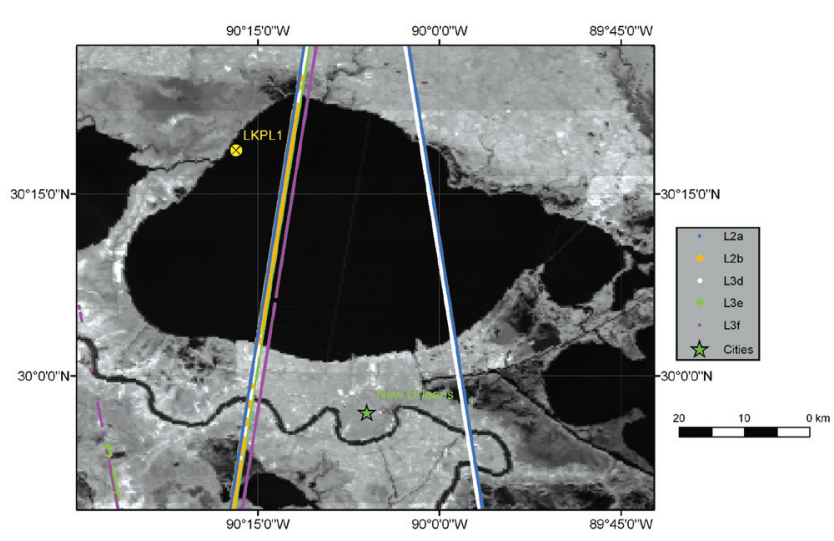

Fig. 8. ICESat tracks through Lake Pontchartrain, Louisiana, USA. The location of the LUMCON tide gauge LKPL1 is designated by the yellow circle-X symbol.

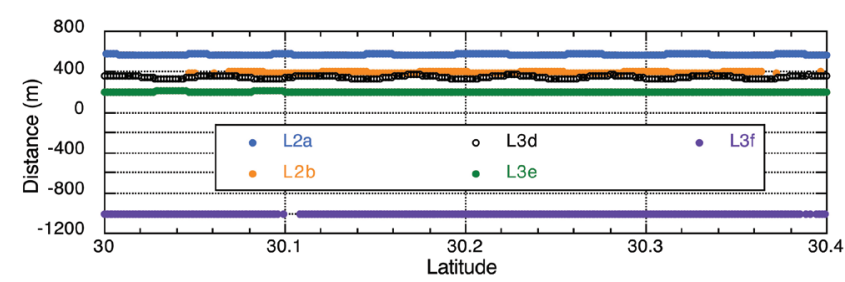

Fig. 9. Distance from the ICESat reference track for passes through Lake Pontchartrain, Louisiana, USA.

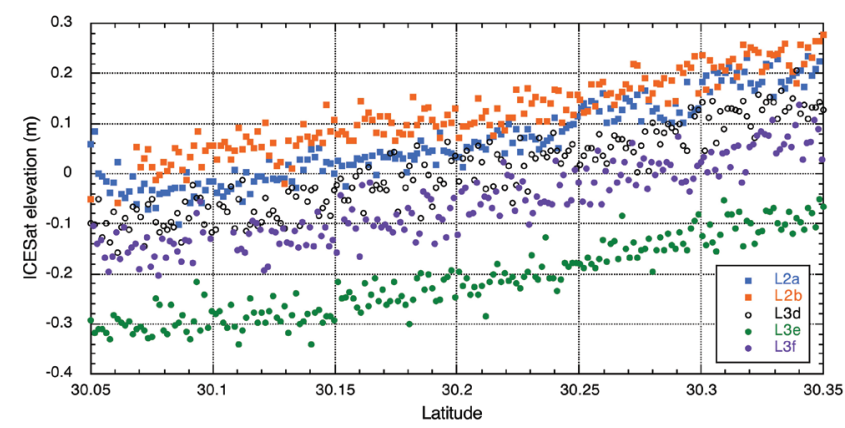

Fig. 10. ICESat elevations with respect to the EGM96 geoid along Lake Pontchartrain, Louisiana, USA. 
L2a (noticeably calmer surface) was affected away from the shoreline (discussed with Fig. 12). ICESat measurements of water level show a relatively steep gradient across the lake. While a small hydrological gradient (or possibly tide error) is possible, the consistent slopes observed are most likely geoid model errors. Lake slope is calculated in the direction of the ICESat tracks, listed in Table 3, and is $\sim 1 \mathrm{~cm} \mathrm{~km}^{-1}$ for all campaigns. Over the three-year span examined the slope increases slightly, although a significant seasonal hydrological signal might be expected but is undetectable from the limited temporal sampling. After removing the average slope $\left(1.229 \mathrm{~cm} \mathrm{~km}^{-1}\right)$ from the data of each campaign, the average of the residuals is calculated and listed in Table 3, after arbitrarily removing the L3e (lowest) elevation as a reference. The RMS about each mean elevation is $\sim 3 \mathrm{~cm}$ (Table 3), which is the anticipated level of precision of the ICESat elevations from other studies (see Section 1.2).

The mean Lake Pontchartrain elevations (Table 3) are plotted with the tide gauge data from LUMCON gauge LKPL1 in Fig. 11. Significant variations are observed in the tide gauge series, and several outliers (data below $1 \mathrm{~m}$ and above $3 \mathrm{~m}$ ) are edited. A 30-day (monthly) smoothing is applied to the tide gauge data (red curve). Since we have augmented the ICESat reference datum (removing the slope and L3e mean) and since the absolute tide gauge reference has not been established (LUMCON, no date), the ICESat time series is arbitrarily shifted to visually match the tide gauge time series. The agreement is good; the ICESat measurements track the same water level changes as the tide gauge, verifying the precision of the measurements and the accuracy of inter-campaign elevation comparisons. Error bars for ICESat are the sum of the RMS of the lake elevations $(3 \mathrm{~cm}$, Table 3) plus $\varepsilon_{h}$ of $2 \mathrm{~cm}$ from Eq. (1) (30 cm for L3f); they are insignificant (and difficult to see) for the fully-calibrated campaigns. Despite its large error bar, L3f elevations match the tide gauge levels too, suggesting at least decimeter-level accuracy at nominal $\left(0.3^{\circ}\right)$ pointing for this data examined at this site. Caution interpreting near-real-time data is still warranted, since every time and location will have a different level of response to the large thermal variations present in near-real-time data (see Section 1.1). Such variations have not been removed in near-real-time data, but they are removed in generating final calibrations (e.g., Release 428 products; see Table 1).

Figure 12 again shows the ICESat elevation across Lake Pontchartrain, but only for campaign L2a. The blue points (same as Fig. 10) include the saturation correction recommended over ice by the ICESat Science Team PRD group (see Section 1.1). The black curve is the GLA06 elevation without saturation correction. During L2a, the nearshore waters of Lake Pontchartrain were apparently highly reflective, causing waveform saturation and lower-than-true elevation measurements. The other campaigns were not affected as dramatically; the scatter of L2a elevations is smaller than that of other campaigns (suggesting a calmer surface; recall Fig. 10). Additionally, the transmitted laser energy was higher during L2a than in subsequent campaigns, supporting a larger potential for saturation. Regardless of the relative influence of these two causes of L2a saturation, this example clearly shows the magnitude and importance of the saturation effect and supports the limited application of the saturation correction in coastal areas.

\section{OPEN OCEAN ISLAND: FUNAFUTI, TUVALU}

The island nations of the world are the most at risk from sea level rise for numerous reasons, producing many different social and economic effects (Leatherman 2001).

Table 3. Mission parameters of 5 laser campaigns examined through Lake Pontchartrain, Louisiana, USA.

\begin{tabular}{|c|c|c|c|c|c|}
\hline Laser campaign & L2a & $\mathbf{L} 2 \mathbf{b}$ & L3d & L3e & L3f \\
\hline Year & 2003 & 2004 & 2005 & 2006 & 2006 \\
\hline Season (N. Hemisphere) & Fall & Winter & Fall & Winter & Spring \\
\hline Date over Pontchartrain $(\mathrm{dd} / \mathrm{mm})$ & $29 / 10$ & $01 / 03$ & $03 / 11$ & $07 / 03$ & $06 / 06$ \\
\hline Pontchartrain slope ${ }^{1}(\mathrm{~cm} / \mathrm{km})$ & 1.038 & 1.090 & 1.093 & 1.140 & 1.160 \\
\hline Pontchartrain elevation ${ }^{2}$ Mean (m) & 0.278 & 0.329 & 0.220 & $0^{3}$ & 0.151 \\
\hline Pontchartrain elevation ${ }^{3}$ RMS (m) & 0.028 & 0.029 & 0.033 & 0.030 & 0.036 \\
\hline
\end{tabular}

${ }^{1}$ Lake slope in the direction of the ICESat tracks, relative to the EGM96 geoid. Negative values indicate a decreasing elevation along the descending tracks.

${ }^{2}$ Lake elevation relative to the lowest campaign (L3e) after removing slope.

${ }^{3}$ Lake elevation $R M S$ about the mean after removing slope. 


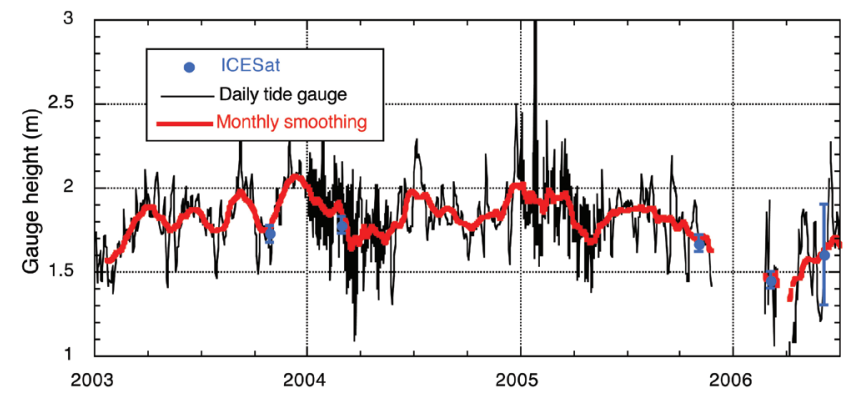

Fig. 11. ICESat and tide gauge water levels in Lake Pontchartrain.

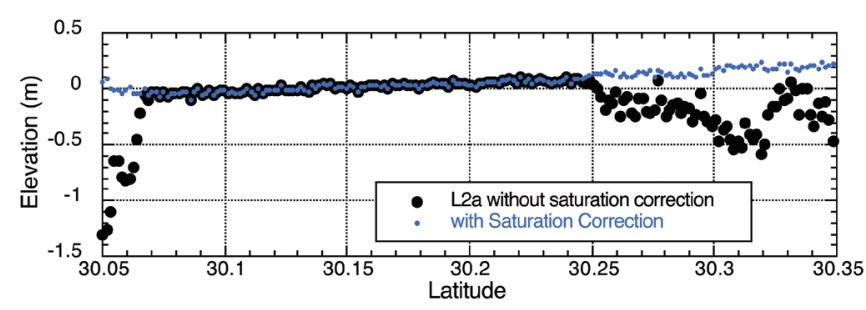

Fig. 12. ICESat elevations along Lake Pontchartrain during L2a. Blue points include the saturation correction, black are without.

The Pacific island nation of Tuvalu is composed of nine major islands composed of numerous (but dwindling) smaller islets. In aggregate, Tuvalu is the fourth-smallest country $\left(26 \mathrm{~km}^{2}\right)$ and has the lowest elevation $(\sim 2 \mathrm{~m})$, with the highest point $\sim 5 \mathrm{~m}$ above sea level. Tuvalu's public notoriety has grown with mainstream concern about sea level rise (e.g., Allen 2004) including the striking geophysical effects to the islands, the potential future refugee status of the entire Tuvalu population, and the potential threat of joining international lawsuits against the largest greenhouse-gasproducing nations in retribution of their plight.
The largest of the Tuvalu islands is Funafuti (Fig. 13), a near-continuous ring of 33 islets, each just 20 to $400 \mathrm{~m}$ wide, around a central lagoon over $20 \mathrm{~km}$ long. The tide gauge near the eastern point of Funafuti is a part of the Joint Archive for Sea Level (JASL) program, now an official Global Sea Level Observing System (GLOSS) data center. JASL maintains data records from two different reference levels (gauge locations) for Funafuti: gauge 025A from 1977 to 1999 and $025 \mathrm{~B}$ from 1993 through the end of 2004; we examine $025 \mathrm{~B}$, but quality-controlled tide gauge data from 2005 - 2006 (during campaigns L3d and L3e) are not yet available. Table 4 lists dates and parameters for each of the

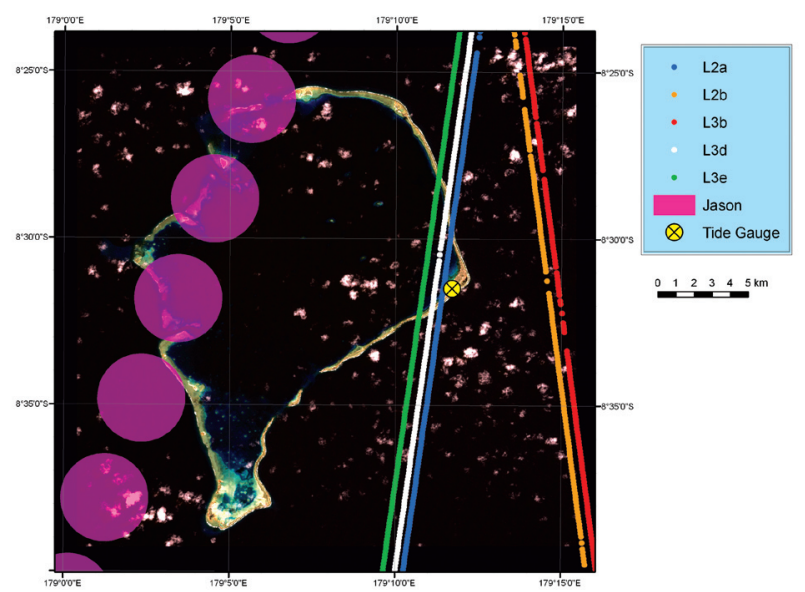

Fig. 13. Landsat image of the capital island of Funafuti, Tuvalu (13 April 2000). The location of a tide gauge (JASL 025B) and ground tracks from five laser campaigns and one Jason-1 repeat cycle are shown. ICESat spots are approximately to scale (50 to $90 \mathrm{~m}$ footprint diameter, see captions: Table 1); theoretical Jason-1 spots are illustrated as $5 \mathrm{~km}$ in diameter to approximate the relative radar footprint size.

Table 4. ICESat data collection for tracks near Funafuti, Tuvalu.

\begin{tabular}{|c|c|c|c|c|c|}
\hline Laser campaign & L2a & $\mathrm{L} 2 \mathrm{~b}$ & L3b & L3d & L3e \\
\hline Year & 2003 & 2004 & 2005 & 2005 & 2006 \\
\hline Season (N. Hemisphere) & Fall & Winter & Winter & Fall & Winter \\
\hline Date $(\mathrm{dd} / \mathrm{mm})$ & $25 / 10$ & $19 / 02$ & $20 / 02$ & $30 / 10$ & $03 / 03$ \\
\hline Pass direction (Ascending/Descending) & $\mathrm{D}$ & A & A & $\mathrm{D}$ & $\mathrm{D}$ \\
\hline Cloud flag (0-15 scale optical depth) & $0,2^{2}$ & 5 & $\mathrm{NA}^{3}$ & $\mathrm{NA}^{3}$ & $0-1$ \\
\hline $1-\sigma$ PAD error $(\operatorname{arcsec})^{1}$ & 1.5 & 1.5 & 1.5 & 1.5 & 1.5 \\
\hline Potential elevation error $\varepsilon_{\mathrm{h}}($ Eq. 1$)(\mathrm{cm})$ & 2 & 2 & 2 & 2 & 2 \\
\hline Mean \pm RMS $1^{\circ}$ north of tide gauge $(\mathrm{cm})$ & $0.3 \pm 4.0$ & $13.1 \pm 5.8$ & $-15.8 \pm 6.4$ & $24.8 \pm 8.8$ & $34.8 \pm 7.7$ \\
\hline Mean \pm RMS $1^{\circ}$ south of tide gauge $(\mathrm{cm})$ & $-0.9 \pm 2.6$ & $3.6 \pm 5.2$ & $-13.6 \pm 4.6$ & $21.2 \pm 4.4$ & $39.7 \pm 5.7$ \\
\hline
\end{tabular}

${ }^{1}$ Fully-calibrated campaigns meet the 1.5 arcsecond (1- $\left.\sigma\right)$ mission goal.

${ }^{2}$ The cloud flag for L2a is 2 north of the island, jumps to 0 at the island/lagoon interface, and remains 0 south of the island.

${ }^{3}$ Not available: the returned energy of the atmospheric laser channel (532 nm, green) fell below the level necessary for satisfactory cloud detection for this channel. 
five fully-calibrated campaigns examined. Theoretical spots from the Jason-1 radar mission are depicted as $\sim 5 \mathrm{~km}$ diameter circles, approximating the larger radar footprints; true radar measurements (1) will not always "lock" at Funafuti due to land contamination, and (2) will be larger ( 8 to $15 \mathrm{~km}$ ) overlapping ellipses depending on wave height (Chelton et al. 2001). Figure 14 shows the cross-track separation distance between the various campaigns. For the descending tracks, L3e lies furthest west, L3d is 600 m east, and L2a is a further $500 \mathrm{~m}$ east. The two ascending tracks examined are about $100 \mathrm{~m}$ apart.

Figure 15 shows a one-second subset (40 shots) of the ICESat elevations (without saturation correction for illustrative purposes) from the L2a tracks crossing the lagoon (see Fig. 13). The latitude scale is reversed to show temporal variations from left to right. The elevations are shown rela-

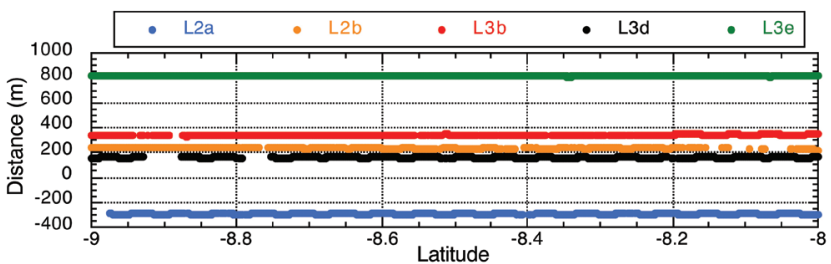

Fig. 14. ICESat spot distance from the reference track for ascending passes (L2b, L3b) and descending passes (L2a, L3d, and L3e). Reference track targeting is not performed in mid-latitudes, and so spot tracks may vary $\pm 2 \mathrm{~km}$ from the reference track (see text). tive to the lagoon average to illustrate relative height differences after the geoid and other effects have been removed. Figure 16 shows the corresponding series of ICESat laser return waveforms. The forty reflected waveforms in Fig. 16 are sorted temporally vertically, i.e., the upper left plot is the $1^{\text {st }}$ laser shot, while the bottom row shows the waveforms from the $5^{\text {th }}, 10^{\text {th }}, 15^{\text {th }}, \ldots .$. and $40^{\text {th }}$ laser shots. Each waveform plot is the return energy $(\mathrm{V})$ versus the time received (ns). The abscissa scale is a constant $125 \mathrm{~ns}$ (400 to $525 \mathrm{~ns}$ ); the ordinate changes dynamically with the energy level. The first 6 shots occur over the open ocean, northeast of the island; these are one-peak waveforms that have basically Gaussian distributions and are typical of unsaturated, cloud-free, open-ocean waveforms from nominal $\left(\theta=0.3^{\circ}\right)$ pointing. The next five shots vary considerably: shots 7 and 8 are very saturated and have uncorrected elevations that are too low (received too much energy reflection from calm near-shore waters), shot 9 is a saturated double peak (a foot-

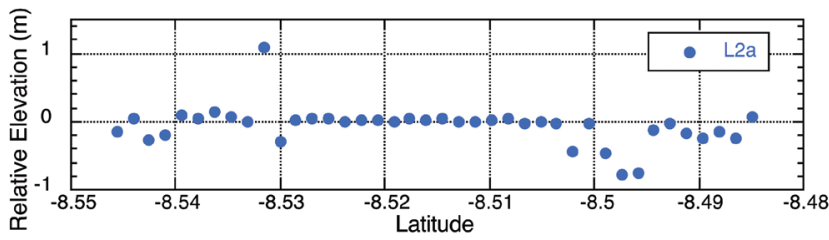

Fig. 15. ICESat elevations spanning 1 second (40 points) over Funafuti. Measurement times increase by $0.025 \mathrm{~s}$ from left to right.
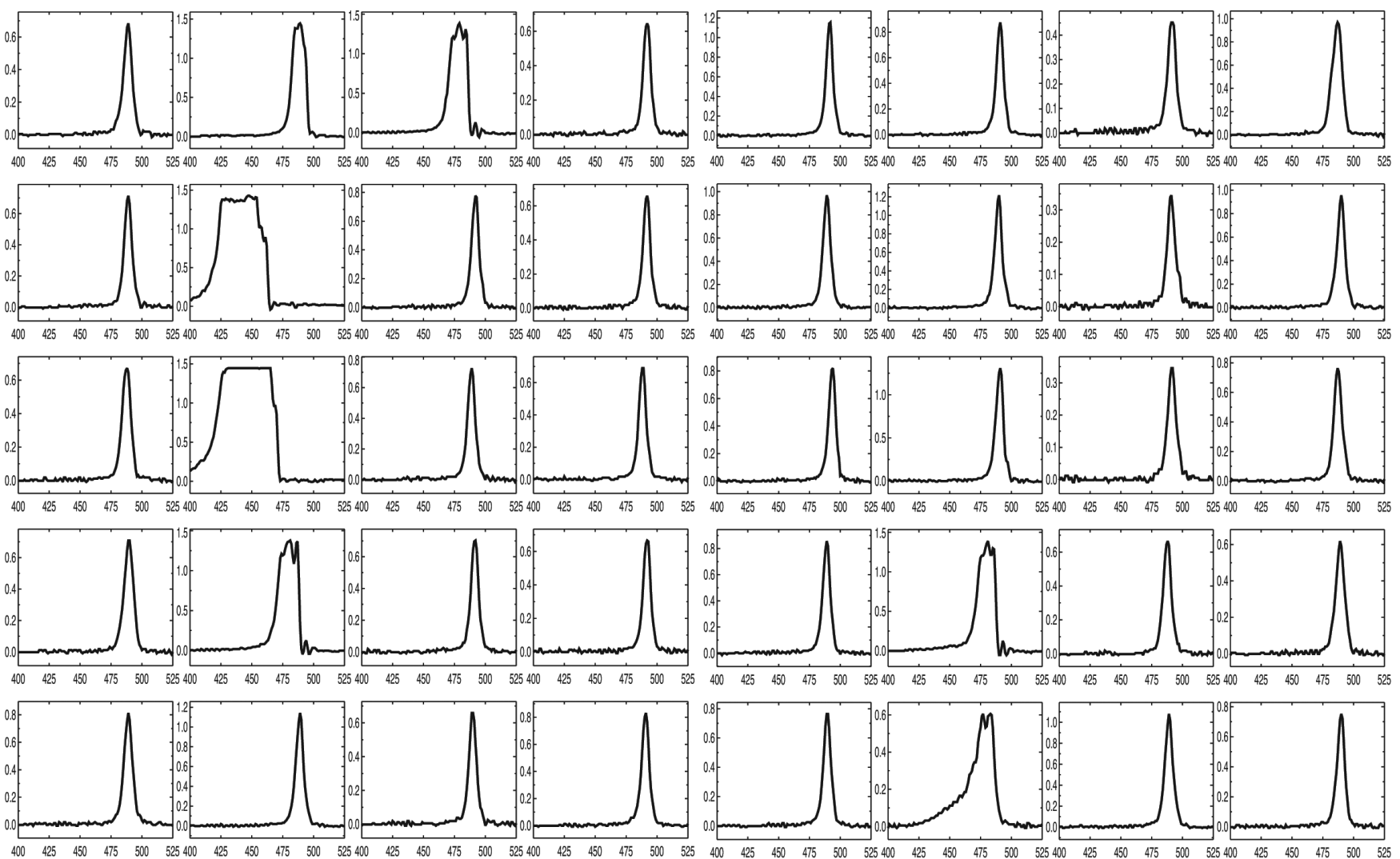

Fig. 16. Forty ICESat waveforms corresponding to the 40 elevations in Fig. 15. 
print covering both land/beach and calm water, encountering either dual ground surface levels or vegetation), shot 10 hits the island (land), and shot 11 falls inside the lagoon near shore and is saturated (elevation too low). When a waveform is saturated, the high level of energy causes a clipping of the peak, which tends to shift the GLA06 (maximum peak) elevation estimate to the right; i.e., the peak is shifted some number of ns later than it should be, and so the two-way travel time (and one-way range) is too long, and the derived elevation is too low. The next seventeen waveforms (shots 12 to 28 ) are near-Gaussian lagoon returns, having slightly narrower waveform widths than the open ocean waveforms due to lower surface roughness (waves and wind effects). Shot 29 is a saturated near-shore lagoon waveform (elevation too low), and shot 30 hits a "tall" area of the island ( $1 \mathrm{~m}$ above measured ocean level). Shots 31 to 40 are again typical non-saturated open-ocean Gaussians. The elevations distinctly outside the lagoon (shots $1-6$ and 31 - 40) are much noisier than across lagoon due to sea state, and hence the elevations occur both above and below the lagoon average; note, however, that twelve of the these sixteen elevations occur below zero, possibly indicating a net average bias effect due to a sea state.

Figure 17 compares the Funafuti tide gauge data (JASL $025 \mathrm{~B}$ at $-8.525^{\circ} \mathrm{N}, 179.195^{\circ} \mathrm{E}$ ), with nearby data from ICESat (L2a, L2b, and L3b), Jason-1 and TOPEX in its interleaved ground track. The radar elevations were selected at the location having the best correlation with the tide gauge data, allowing for spatial and temporal lag-time variability (Mitchum 1994, 1998; Hayes 2002). For the ICESat elevations, the limited temporal sampling prohibits a meaningful lag correlation, and so a $1^{\circ}$ mean was selected in order to average ICESat on a larger scale, north and south of the tide gauge (Table 4). The L2a and L3b averages match the tide gauge to within the variability observed from radar altimetry. L2a averages north and south match, despite having different cloud flags ( 2 north, 0 south), indicating no apparent elevation degradation from thin clouds. L2b does not match the tide gauge, and has a large variation between the north and south averages. These discrepancies may be caused by cloud interference (cloud flag $=5$ ). This example should be revisited when a forward scattering (ERD) correction is available.

\section{INLAND RIVER: TAPAJOS RIVER, BRAZIL}

The Amazon is noteworthy as the largest fresh water transport system in the world. The enormous hydrological cycle throughout the Amazon Basin is detectable from space [e.g., via gravity signature (Tapley et al. 2004)]. The hydrological changes in the region directly impact indigenous peoples, but also affect one of the world's most biologically diverse areas (Myers et al. 2000), which is also globally critical in terms of forest dynamics and the carbon cycle (Asner et al. 2004). Here we examine ICESat along one of the largest tributaries of the Amazon, the Tapajos River in central Brazil, flowing south to north at $\sim 304^{\circ} \mathrm{E}$ longitude (Fig. 18).

Satellite radar altimetry over lakes, the Amazon, and other large rivers has been examined for a couple decades (e.g., Rapley et al. 1987; Koblinsky et al. 1993; Birkett 1995, 1998; Birkett et al. 2002; Cazenave et al. 1997). For rivers, the minimum detection level under ideal conditions (an inundated floodplain) is $\sim 1 \mathrm{~km}$, with accuracies estimated from tens of $\mathrm{cm}$ to several meters (Birkett et al. 2002). The small footprint (50 to $90 \mathrm{~m}$, Table 1) and high-data rate (40 Hz, $\sim 170 \mathrm{~m}$ footprint separation) of ICESat laser altimetry suggest great potential applications from denser measurements and to smaller waters than possible from radar. Radar also has measurement difficulty during low-water levels due to emerging land and vegetation (Birkett et al. 2002), which is not a problem for ICESat. Given the general north-south orientation of satellite ground tracks, frequent sampling of east-west rivers such as the Amazon will oc-

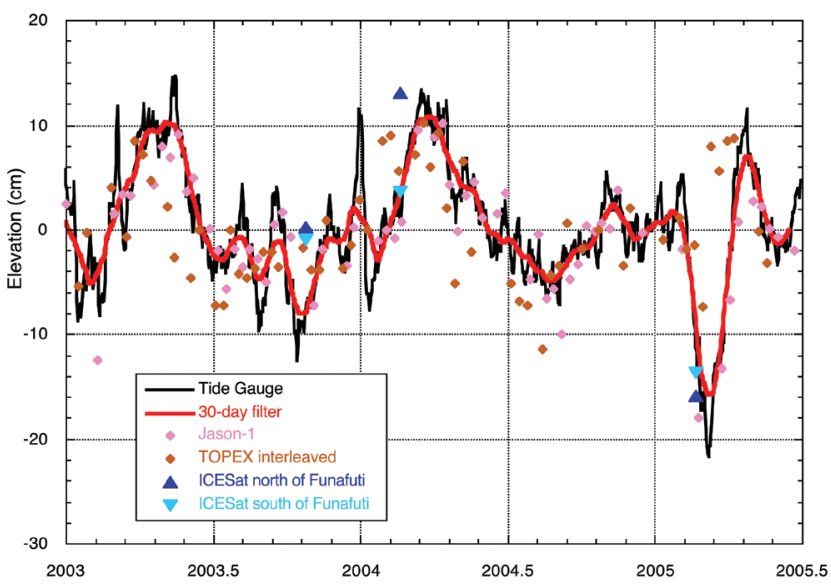

Fig. 17. Sea level from the Funafuti tide gauge (black, red), ICESat (blues), Jason-1 (pink), and TOPEX interleaved (tan) altimetry. For ICESat, elevations north of the island are plotted dark blue, south light blue.

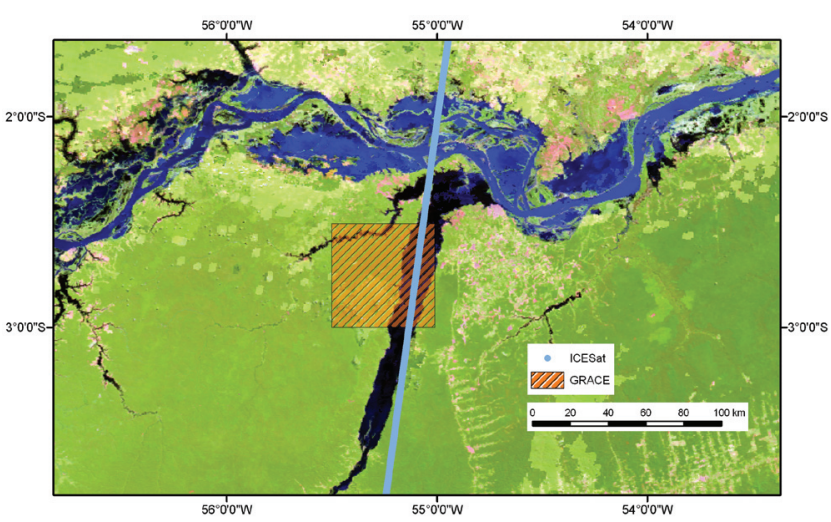

Fig. 18. The Tapajos and Amazon rivers in central Brazil and an ICESat 8-day repeat orbit ground track. Dashed box marks the size of the GRACE geoid grid. 
cur in many different locations. North-south rivers (like Tapajos) will be sampled less frequently, but in these cases the ICESat elevation profiles can be used to estimate river slope, shown to better than $0.001^{\circ}$ precision (Harding and Jasinski 2004). Dense and precise ICESat data can also be used to validate radar altimetry (e.g., Frappart et al. 2005).

One of ICESat's 8-day repeat calibration orbit ground tracks serendipitously passes along a $\sim 50 \mathrm{~km}$ stretch of the Tapajos river (Schutz 2004) (Fig. 18); the river and the ICESat track are even roughly aligned in the same direction (have similar azimuths), increasing the prospective data collection. Consequently, ICESat data along Tapajos represents one of the longest and densest ( $\sim 300$ elevation points), repeatable elevation measurements of any river ever achieved from space. The MODIS image in Fig. 18 shows the path of the ICESat descending 8-day repeat orbit track (blue). The hashed box marks the boundary of the closest GRACE geoid sample bin (compared later), as supplied in a $0.5^{\circ}$ by $0.5^{\circ}$ grid (S. Bettadpur, personal communication, 2006).

On the scale of Fig. 18, the ICESat tracks along the Tapajos appear coincident. Figure 19 shows detailed locations of the ICESat laser spots along the Tapajos with respect to the targeted reference track. Data from campaigns L2a (blue), L3b (red), and L3e (green) are nearly coincident (top plot), and are shown to overlap (bottom plot) within a $\sim 100 \mathrm{~m}$ band. The high-frequency variations are caused by the pointing control response to solar panel motion, approximately a $1 \mathrm{~Hz}$ signal, which is correctly captured by the PAD procedure. L3f (geolocation not fully calibrated), L3a, and L1a are, respectively, further west by $\sim 250, \sim 750$, and $\sim 1750 \mathrm{~m}$. Table 5 lists relevant statistics for the six laser campaigns considered here; the target was not actively pointed at until after L2b, and during L3d the region was cloudy (optically opaque). In order to point at the 8-day track from the 91-day orbit, an off-nadir pointing maneuver is performed. In ad-

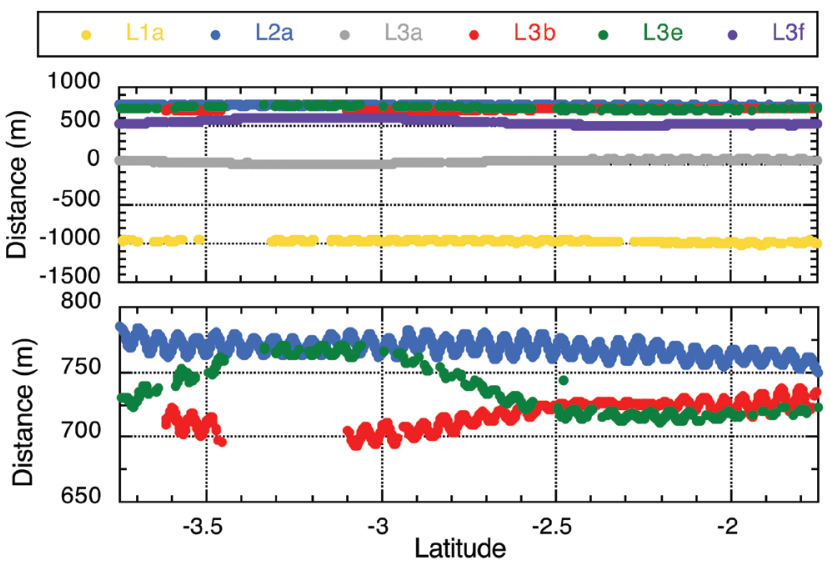

Fig. 19. ICESat laser spot distances from the reference 8-day calibration orbit ground track along the Tapajos River. Spread of 6 campaigns is within $2 \mathrm{~km}$ (top). Data from campaigns L2a (blue), L3b (red), and L3e (green) are nearly coincident (bottom), given 50 to $90 \mathrm{~m}$ spot sizes (captions: Table 1). dition to the nominal $0.3^{\circ}$ pitch forward, the satellite performs a roll maneuver to align the ground spots along the 8-day reference orbit track, yielding a total off-nadir angle of $\sim 2.6^{\circ}$. PAD errors in Table 5 are repeated from Table 1 and are used in conjunction with the off-nadir pointing angles $(\theta)$ to estimate the potential elevation error [ $\varepsilon_{h}$, Eq. (1)]. Note that L3f is not yet fully calibrated, and so pointing errors contribute to elevation error at approximately an order of magnitude larger than the fully-calibrated campaigns. L1a has undergone limited PAD refinement, but since the off-nadir angle is small (nominal $\theta=0.3^{\circ}$ ), its $\varepsilon_{h}$ is still relatively small $(15 \mathrm{~cm})$. Potential horizontal errors $\left(\varepsilon_{x}\right)$ are also calculated [(via Eq. (2)] and are inconsequential for the applications presented here, even if L3f footprints locations have a $58 \mathrm{~m}$ position error. Each particular application situation determines what errors are significant when considering near-real-time data.

Figure 20 shows the ICESat elevations from six laser campaigns along the Tapajos. Plot scatter and data gaps along the river correspond to cloud interference (there is little waveform saturation). The magnitudes of the cloud optical depth flag and RMS of the elevations (Table 5) appear correlated. This suggests that forward scattering (the ERD correction) is a very important consideration in the ongoing calibration activities of the ICESat Science Team. A preliminary ERD correction for L2a exists, but since no clouds were observed over Tapajos during L2a (flag $=0)$, the ERD correction cannot be evaluated here. Regardless, the average river stage changes between campaigns measured by ICESat are on the order of meters and so the results presented here will not be significantly altered by an additional ERD (cm-to-dm level) range correction.

The Tapajos river stage for each campaign is averaged over the span of the river (from 2.5 to $3.0^{\circ} \mathrm{S}$ ), the mean (listed in Table 5) of each time series is removed, and the resulting residual elevations are plotted in Fig. 21, with a 10 -point $(0.25$ second) boxcar filter applied. Very well defined structures are apparent. The first two campaigns [L1a (yellow) and L2a (blue)] show similar characteristics within $\pm 5 \mathrm{~cm}$ (despite having a large cross-track separation), including a slow rise $\left(\sim 0.25 \mathrm{~cm} \mathrm{~km}^{-1}\right)$ from 3.0 to $2.6^{\circ} \mathrm{S}$, then a rapid decrease $\left(\sim 1 \mathrm{~cm} \mathrm{~km}^{-1}\right)$ during the last $0.1^{\circ}$ of latitude. L3b (red) starts similarly, then exhibits a large 10 to $15 \mathrm{~cm}$ rise and fall centered near $2.6^{\circ} \mathrm{S}$. L3a (grey) and L3f (purple) are different from the others, but begin similar to each other, then deviate near $2.6^{\circ} \mathrm{S}$. The apparent variability near the confluence with the Amazon could be tidal influence. The large variations could also be due to ICESat capturing flood waves. Future research should be directed toward a more complete analysis of this and other rivers, including the collection of precipitation and river gauge data for verification.

Figure 22 shows the average river stage measured by ICESat (Table 5) from 2003 to 2006. The RMS of this av- 
Table 5. ICESat data collection campaigns over Tapajos.

\begin{tabular}{|c|c|c|c|c|c|c|}
\hline Laser campaign & L1a & $\mathbf{L 2 a}$ & $\mathbf{L 3 a}$ & $\mathbf{L 3 b}$ & L3e & L3f \\
\hline Year & 2003 & 2003 & 2004 & 2005 & 2006 & 2006 \\
\hline Season (N. Hemisphere) & Winter & Fall & Fall & Winter & Winter & Spring \\
\hline Date $(\mathrm{dd} / \mathrm{mm})$ & $25 / 02$ & $29 / 09$ & $19 / 10$ & $06 / 03$ & $10 / 03$ & $09 / 06$ \\
\hline Repeat orbit (days) & 8 & 8 & 91 & 91 & 91 & 91 \\
\hline Off-nadir pointing angle $\theta\left(^{\circ}\right)$ & 0.3 & 0.3 & 2.6 & 2.6 & 2.6 & 2.6 \\
\hline Cross-track distance from reference (m) & -1000 & 775 & 0 & 725 & 725 & 500 \\
\hline 1- $\sigma$ PAD error (arcseconds) ${ }^{1}$ & 10 & 1.5 & 1.5 & 1.5 & 1.5 & 20 \\
\hline Potential elevation error $\varepsilon_{h}$ [Eq. (1)] (m) & 0.15 & 0.02 & 0.02 & 0.02 & 0.02 & 2.60 \\
\hline Potential horizontal error $\varepsilon_{x}$ [Eq. (2)] (m) & 29 & 4 & 4 & 4 & 4 & 58 \\
\hline Cloud flag (0-15 scale optical depth) & $0-1$ & 0 & $0-4$ & $\mathrm{NA}^{2}$ & $9-15$ & $3-5$ \\
\hline Mean of river elevations 2.5 to $3.0^{\circ} \mathrm{S}(\mathrm{m})$ & 7.96 & 5.85 & 4.67 & 6.98 & 8.48 & 8.84 \\
\hline RMS of river elevations 2.5 to $3.0^{\circ} \mathrm{S}$ (m) & 0.03 & 0.03 & 0.08 & 0.09 & 0.25 & 0.15 \\
\hline
\end{tabular}

${ }^{1}$ Fully-calibrated campaigns meet the 1.5 arcsecond 1- $\sigma$ mission goal; errors for campaigns L1a and L3f are estimated from observed improvements to fully-calibrated campaigns (S. Bae and C. Webb, personal communication, 2006).

${ }^{2}$ Not available: the returned energy of the atmospheric laser channel (532 $\mathrm{nm}$, green) fell below the level necessary for satisfactory cloud detection.

erage is recorded in Table 5, and is $3 \mathrm{~cm}$ under clear conditions, approximately the ICESat measurement precision. Error bars plotted on each ICESat river level average are the sum of $\varepsilon_{h}$ and the RMS table rows. The best-fit annual sinusoid was superimposed on the ICESat measurements (dashed blue curve), and it has an annual peak amplitude at day 112 (22 April) ( \pm 12 days formal error). Next, the $0.5^{\circ}$ by $0.5^{\circ}$ GRACE geoid grid encompassing Tapajos (see Fig. 18) is extracted from the global monthly harmonic time series (data release RL01), plotted (black squares), and fit with an annual curve. The GRACE data are spatially averaged over $\sim 1000 \mathrm{~km}$ and do not support $0.5^{\circ}$ resolution; however, the purpose of the comparison is to determine whether the river levels observed by ICESat correspond to the large-scale pattern of regional water change (see Tapley et al. 2004) in lieu of in-situ stage data. The peak of the GRACE geoid change (total water mass) occurs on day 128 (8 May) ( \pm 3 days formal error). The important result is that the phases of the ICESat and GRACE time series nearly agree within their formal errors, and they bookend an independent estimate of peak Tapajos flow on day 121 (1 May) from TOPEX (Birkett et al. 2002). This demonstrates that the broad-scale water storage (phase) measured by GRACE is directly proportional to the local-scale Tapajos river stage measure by ICESat, and that ICESat and TOPEX agree despite different time spans and instrumentation, illustrating the range of scale and supporting the persistence of this hydrological signal. In 2006, both GRACE and ICESat display variations noticeably higher than the average annual amplitude. ICESat campaign L3f is not yet fully calibrated, as

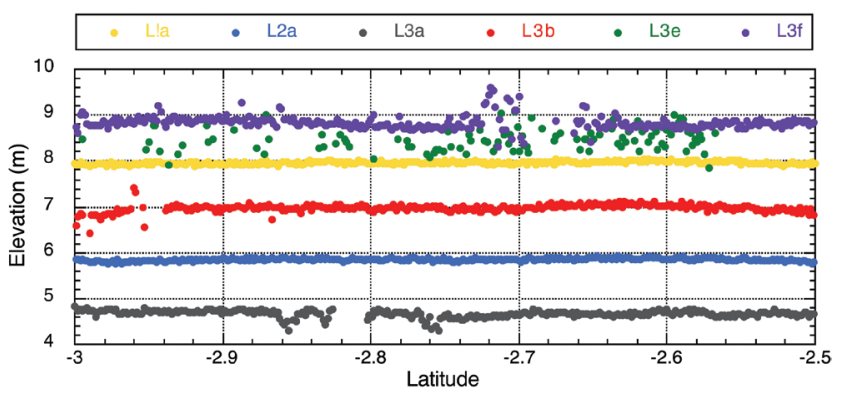

Fig. 20. ICESat elevations of Tapajos river, Brazil, with respect to the EGM96 geoid from 6 laser campaigns (Table 5). Data gaps and areas of higher noise can be attributed to clouds. Meter-level hydrological changes are observed.

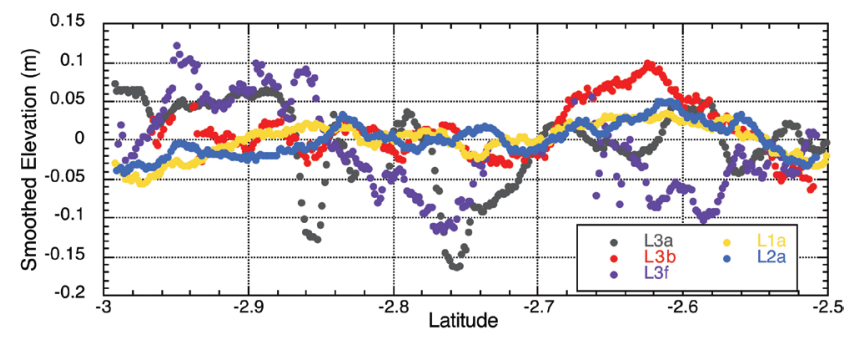

Fig. 21. Smoothed ICESat elevations along Tapajos, with mean values (Table 5) removed. A 10-point ( 0.25 second) filter is applied. L3e is not included due to significant cloud interference. 


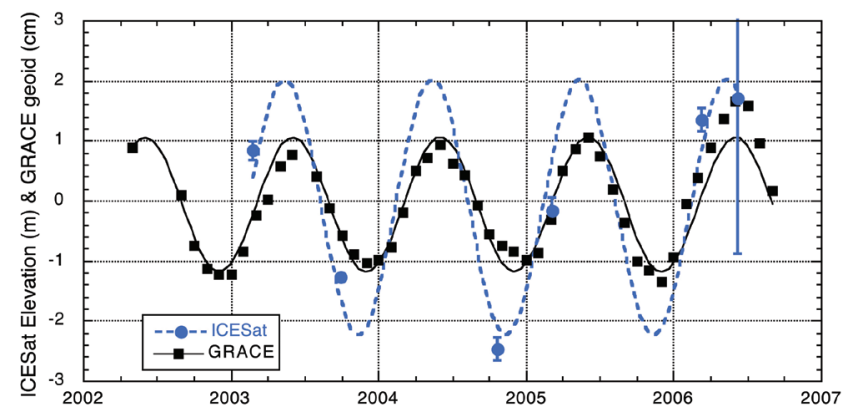

Fig. 22. Tapajos average river elevation measured by ICESat, and GRACE geoid height (implied water mass) change from a $0.5^{\circ} \times 0.5^{\circ}$ grid encompassing the river (see Fig. 18). ICESat error bars are the sum of the E'h and RMS rows in Table 5. Best-fit annual curves are estimated, yielding peaks for ICESat at $112 \pm 12$ days and for GRACE at $128 \pm 3$ days (formal errors).

shown by its large potential error bar, but appears to fit well with the GRACE-observed hydrological signal.

Figure 23 shows the vegetation heights along the Tapajos-Amazon confluence, as estimated by the ICESat waveform method described in Section 2. Four campaigns are shown (L2a, L3b, L3e, and L3f), those having tracks closest to each other (see Fig. 19). The vegetation heights are calculated from the elevations derived from the first peak (canopy) minus the last peak (surface) of all multiplepeak waveforms (e.g., Figs. 4e, f). Single-peak waveforms correspond to river surface measurements, which lead to $0 \mathrm{~m}$ vegetation heights (i.e., none). Terrain variability is neglected, which introduces complications in the interpretation of multiple-peak waveforms (Harding and Carabajal 2005). The data from the four campaigns generally agree on vegetation location, height, and height variance. Between 1.5 and $2.5^{\circ} \mathrm{S}$, a mixture of water and vegetation measurements are observed at the confluence of the two rivers, as suggested by the MODIS image (Fig. 18), with height groupings approximately 20,10 , and $30 \mathrm{~m}$ high, respectively northward. At $2.7^{\circ} \mathrm{S}$, both L3e and L3f campaigns detect a low relief object ( 2 to $3 \mathrm{~m}$ ) for 2 to 3 shots. Given the optical depth of these passes (see Table 5), it is more likely that mist or fog created a double peak waveform, rather than other hypotheses (e.g., vegetation or a boat in the middle of the river); again, cloud effects emerge as an important topic of ongoing calibration and validation. Below $3.0^{\circ} \mathrm{S}$, as the ICESat tracks veer east of the river (see Fig. 18), there is a $\sim 20 \mathrm{~km}\left(\sim 0.2^{\circ}\right)$ region of mixed vegetation and surface (water), presumably where ICESat encounters the riverbank and flood zone. Moving further southward, maximum vegetation heights increase dramatically from 15 to $35 \mathrm{~m}$ (and up to $\sim 60 \mathrm{~m}$, not shown), as the laser apparently fails to detect undergrowth through ever-taller vegetation. Several scattered vegetation heights below $10 \mathrm{~m}$ suggest limited returns from undergrowth, while surface detection still occurs (a necessary condition for the canopy minus ground cal- culation). To clarify the issue we plot (Fig. 24) vegetation height as a function of the number of peaks detected in each waveform, ideally the number of distinct reflectors within each footprint. The linear relationship in Fig. 24 is obvious and logical: a larger number of reflectors per footprint (suggesting more/denser vegetation) are correlated with higher vegetation height estimates (more/taller vegetation). The most important result stemming from Fig. 24 is that the approximate range of vegetation detection is $\sim 15 \mathrm{~m}$ regardless of the number of reflectors; this suggests that, in this dense tropical Brazilian vegetation, ICESat cannot detect energy returned from undergrowth more than $\sim 15$ m below the canopy top, but can still detect a surface reflection. Verification of this conjecture requires an independent measurement (in situ most valued) either here or in another similar tropical climate. Note that the $\sim 35 \mathrm{~m}$ limit was artificially created in this study from the arbitrary selection of 240 bins from each waveform (each ns corresponds to $0.15 \mathrm{~m}$, so the limit is $36.0 \mathrm{~m}$ ). Future investigation will allow for taller trees, as well as examine other tropical areas, compare with other types of vegetation, and explore the incorporation of surface water under vegetation into hydrological research.

\section{SUMMARY}

ICESat laser altimetry measurements provide unprecedented detail of coastal regions, including accurate and precise water levels, seamless land-water transitions, and

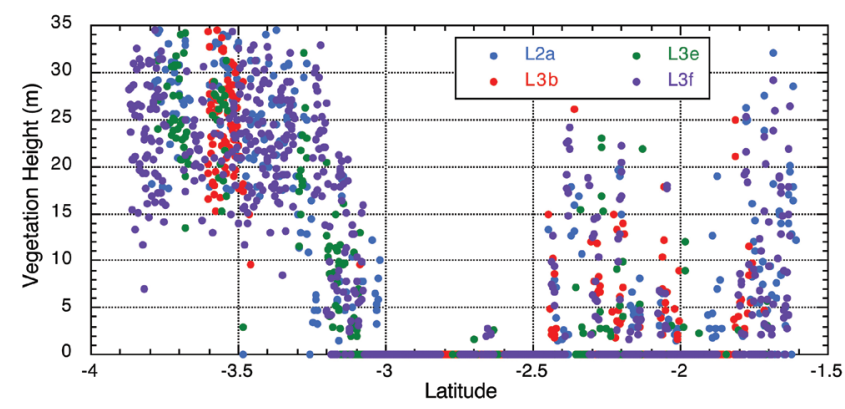

Fig. 23. ICESat vegetation height estimates (canopy-ground) along the confluence of Tapajos and Amazon rivers, Brazil, from 4 laser campaigns. Heights reported as $0 \mathrm{~m}$ represent single-peak surface waveforms (water surface).

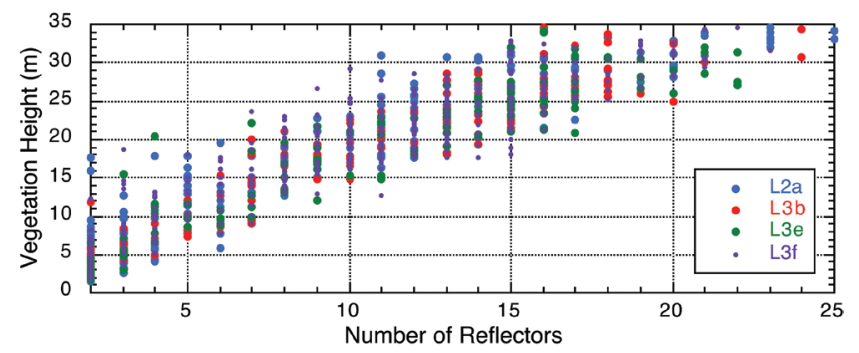

Fig. 24. ICESat waveform-estimated vegetation heights as a function of the number of reflectors (peaks) within the waveform. 
coastal vegetation heights. Along the Louisiana-Mississippi Gulf Coast, USA, the small GLAS footprint (50 to $90 \mathrm{~m}$ ) and high along-track resolution $(40 \mathrm{~Hz}, \sim 170 \mathrm{~m})$ of ICESat detect tidal and/or weather signatures in small basins and the Mississippi River. Vegetation heights are estimated along tracks spanning the river delta and coast. We detect coastal vegetation heights significantly lower after Hurricane Katrina than before near Bay Saint Louis, Mississippi: the decrease in mean vegetation heights is $\sim 5 \mathrm{~m}$, and the decrease in maximum heights is 10 to $20 \mathrm{~m}$. A lake slope is detected of $\sim 1 \mathrm{~cm} \mathrm{~km}^{-1}$, either hydrological or more likely due to geoid error. The RMS of the along-track lake measurements is $\sim 3 \mathrm{~cm}$ for all laser campaigns examined, supporting other estimates of ICESat measurement precision. After removing the local slope, the ICESat measurements of Lake Pontchartrain match a local tide gauge to better than decimeter level for inter-campaign comparisons. Waveform saturation is observed across Lake Pontchartrain during L2a, and the application of the ICESat saturation correction successfully corrects the coastal elevation data; a continued saturation analysis effort is still warranted.

In the open ocean near Funafuti, Tuvalu, RMS averages are 3 to $9 \mathrm{~cm}$, while across the Funafuti lagoon the RMS is $3 \mathrm{~cm}$. ICESat provides highly detailed information about the elevation and waveforms across transitions from the open ocean to land to lagoon and back across the island. ICESat water elevations match Jason-1, TOPEX, and tide gauge data at Funafuti, albeit with limited temporal sampling.

ICESat measurements along the Tapajos River, Brazil, represent one of the longest $(\sim 50 \mathrm{~km})$ densest $(\sim 300$ measurements) and most repeatable records of inland river elevations from space. Meter-level river variations are detected, which are in phase with annual GRACE geoid (water mass) signals and earlier TOPEX results, illustrating the scales and persistence of the regional hydrological change and the usefulness of ICESat to river stage detection. The RMS of river elevations is $3 \mathrm{~cm}$ under clear conditions, 8 to $15 \mathrm{~cm}$ under partly-cloudy skies, and $25 \mathrm{~cm}$ under heavy clouds. The ICESat forward scattering (ERD) correction is an important topic for future calibration efforts, as supported by this and other examples shown. Correlated river topography (whether from tides, flood waves, or other effects) are observed, yielding detailed river slope information. Subcanopy surface water is detected, and a $\sim 15 \mathrm{~m}$ vegetation penetration limit is observed in the tropical Brazilian vegetation, while apparently maintaining surface detection (neglecting surface roughness).

These examples show a small sample of ICESat's utility to continental coast, open-ocean island, and inland water investigations. The global ICESat data set can provide unprecedented detail over all land types: ice, land, and water surfaces, and most importantly their transitional regions, thanks to the small footprint (50 to $90 \mathrm{~m}$ ), high along-track resolution $(40 \mathrm{~Hz}, \sim 170 \mathrm{~m})$, and high precision $(\sim 3 \mathrm{~cm})$ of ICESat.

Acknowledgements This research was performed at the University of Texas at Austin Center for Space Research (UTCSR), USA, in support of ICESat. We are grateful to NASA for this funding provided through contract/grant NAS5-99005 and NNG06GA99. ICESat data are distributed to the ICESat Science Team by the NASA Science Computing Facility; identical ICESat data products from fully-calibrated laser campaigns and analysis software are publicly available through NSIDC at http://www.nsidc.org. Thanks to UTCSR personnel Robert Harpold, Charles Webb, Sungkoo Bae, and Srinivas Bettadpur for assistance, and thanks to an anonymous reviewer for detailed comments and suggestions. MODIS images of the Louisiana-Mississippi Gulf Coast and Tapajos were obtained from the UTCSR MODIS Archive. The Landsat image of Funafuti was obtained from the Global Land Cover Facility (http://glcf.umiacs.umd. edu). Lake Pontchartrain tide gauge data were obtained from the Louisiana Universities Marine Consortium (http:// weather.lumcon.org). The Funafuti tide gauge data are part of the Joint Archive for Sea Level (JASL), a collaboration between the University of Hawaii Sea Level Center and the World Data Center-A for Oceanography, the National Oceanographic Data Center, and the National Coastal Data Development Center, funded by the National Ocean Service of the National Oceanic and Atmospheric Administration, with support from the JASL (http://uhslc.soest.hawaii.edu).

\section{REFERENCES}

Abshire, J. B., X. Sun, H. Riris, J. M. Sirota, J. F. McGarry, S. Palm, D. Yi, and P. Liiva, 2005: Geoscience Laser Altimeter System (GLAS) on the ICESat mission: Onorbit measurement performance. Geophys. Res. Lett., 32, L21S02, doi: 10.1029/2005GL024028.

Afzal, R. S., and J. L. Dallas, 2001: GLAS Laser Transmitters, Science Team Review, NASA Goddard Space Flight Center.

Allen, L., 2004: Tuvalu: That sinking feeling (cover article). Smithsonian, August, 44-52.

Asner, G. P., D. Nepstad, G. Cardinot, and D. Ray, 2004: Drought stress and carbon uptake in an Amazon forest measured with spaceborne imaging spectroscopy. Proceedings of the National Academy of Science, 2004, 101, 6039-6044, originally published online 7 April 2004, doi: 10.1073/pnas.0400168101.

Bae, S., and B. E. Schutz, 2000: Laser pointing determination using stellar reference system in geoscience laser altimeter system, presented at the AAS/AIAA Space Flight Mechanics Conf., Clearwater, FL, AAS 00-123.

Bae, S., and B. E. Schutz, 2002: Precision attitude determination (PAD), Geoscience Laser Altimeter System 
(GLAS) Algorithm Theoretical Basis Document Version 2.2, http://www.csr.utexas.edu/glas/pdf/atbd pad 10 02.pdf, last accessed 25 April 2007.

Birkett, C. M., 1995: The contribution of TOPEX/POSEIDON to the global monitoring of climatically sensitive lakes. J. Geophys. Res., 100, 25179-25204.

Birkett, C. M., 1998: The contribution of the TOPEX (NRA) radar altimeter to the global monitoring of large rivers and wetlands. Water Resour. Res., 34, 1223-1240.

Birkett, C. M., L. A. K. Mertes, T. Dunne, M. H. Costa, and M. J. Jasinski, 2002: Surface water dynamics in the Amazon Basin: Application of satellite radar altimetry. J. Geophys. Res., 107, 8059, doi: 10.1029/ 2001JD000609.

Brenner, A., H. Zwally, C. Bentley, B. Csatho, D. Harding, M. Hofton, J. Minster, L. Roberts, J. Saba, R. Thomas, and D. Yi, 2003: Derivation of range and range distributions from laser pulse waveform analysis for surface elevations, roughness, slope and vegetation heights, Geoscience Laser Altimeter System (GLAS) Algorithm Theoretical Basis Document Version 4.1, http:// www.csr.utexas.edu/glas/pdf/Atbd 20031224.pdf, last accessed 25 April 2007.

Brown, A., B. Csatho, C. Y. Kuo, and Y. Yi, 2004: ICESat validation in Great lakes using tide gauge and radar altimetry data, geophysical research abstracts, 6, EGU General Assembly Abstract EGU04-A-06110-1.

Calmant, S., and F. Seyler, 2006: Continental surface waters from satellite altimetry, C. R. Geosci., 338, 11131122.

Carabajal, C., J. Boy, S. Luthcke, D. Harding, D. Rowlands, and F. Lemoine, 2006: Recovery of the three-gorges reservoir impoundment signal from ICESat altimetry and GRACE. EOS Trans. AGU, 87, Fall Meet. Suppl., Abstract G13C-06.

Cazenave, A., P. Bonnefond, K. Dominh, and P. Schaeffer, 1997: Caspian sea level from Topex-Poseidon altimetry: Level now falling. Geophys. Res. Lett., 24, 881884.

Chelton, D. B., J. C. Ries, B. J. Haines, L. L. Fu, and P. S. Callahan, 2001: Satellite altimetry. In: Fu, L. L., and A. Cazenave (Eds.), Satellite Altimetry and Earth Sciences, Int. Geoph. Series, 69, Academic Press.

Drake, J. B., R. Dubayah, R. G. Knox, D. B. Clark, and J. B. Blair, 2002: Estimation of tropical forest structural characteristics using large-footprint lidar. Remote Sens. Environ., 79, 305-319.

Frappart, F., A. Cazenave, F. Seyler, and S. Calmant, 2005: Comparisons of the ENVISAT waveform retrackers over inland waters, Proc. of the 2004 ENVISAT and ERS Symposium, Salzberg, Austria, 6 - 10 September, 2004, ESA SP-572.

Fricker, H., A. Borsa, B. Minster, C. Carabajal, K. Quinn, and B. Bills, 2005: Assessment of ICESat performance at the salar de Uyuni, Bolivia. Geophys. Res. Lett., 32, L21S06, doi: 10.1029/2005GL023423.

Harding, D. J., and M. F. Jasinski, 2004: ICESat Observations of inland surface water stage, slope and extent: A new method for hydrologic monitoring. EOS Trans. AGU, 85, Fall Meet. Suppl., Abstract C21B-05.

Harding, D. J., and C. C. Carabajal, 2005: ICESat waveform measurements of within-footprint topographic relief and vegetation vertical structure. Geophys. Res. Lett., 32, L21S10, doi: 10.1029/2005GL023471.

Hayes, S., 2002: The determination of relative biases between satellite altimeters using tide gauge data, CSR Tech. Memo-03-01, Center for Space Research, University of Texas at Austin.

Herring, T. A., and K. Quinn, 1999: Atmospheric delay correction to GLAS laser altimeter ranges, Geoscience Laser Altimeter System (GLAS) Algorithm Theoretical Basis Document Version 1.0, http://www-gpsg. mit.edu/ tah/ICESat/MIT.ATBD.Vers.2.1.pdf, last accessed 25 April 2007.

IPCC (Intergovernmental Panel on Climate Change), 2001: Contribution of Working Group I to the Third Assessment Report of the Intergovernmental Panel on Climate Change. In: Houghton, J. T., Y. Ding, D. J. Griggs, M. Noguer, P. J. van der Linden, X. Dai, K. Maskell, and C. A. Johnson (Eds.), Cambridge University Press, Cambridge, United Kingdom and New York, NY, USA, $881 \mathrm{pp}$.

Koblinsky, C. J., R. T. Clarke, A. C. Brenner, and H. Frey, 1993: Measurement of river level variations with satellite altimetry. Water Resour. Res., 29, 18391848.

Lancaster, R. S., J. D. Spinhirne, and S. P. Palm, 2005: Laser pulse reflectance of the ocean surface form GLAS satellite lidar. Geophys. Res. Lett., 32, L22S10, doi: 10.01029/2005GL023732.

Leatherman, S. P., 2001: Social and economic costs of sea level rise. In: Douglas, B. C., M. S. Kearney, and S. P. Leatherman (Eds.), Sea Level Rise and Consequences, Academic Press, San Diego.

Lefsky, M. A., D. J. Harding, M. Keller, W. B. Cohen, C. C. Carabajal, F. Del Bom Espirito-Santo, M. O. Hunter, and R. de Oliveira Jr., 2005: Estimates of forest canopy height and aboveground biomass using ICESat. Geophys. Res. Lett., 32, L22S02, doi: 10.1029/2005GL023971.

LUMCON (Louisiana Universities Marine Consortium), no date: http://weather.lumcon.edu, last accessed 25 April 2007.

Luthcke, S. B., D. D. Rowlands, J. J. McCarthy, D. E. Pavlis, and E. Stoneking, 2000: Spaceborne laser altimeter pointing bias calibration from range residual analysis. J. Spacecr. Rockets, 37, 374-384.

Luthcke, S. B., D. D. Rowlands, T. A. Williams, and M. Sirota, 2005: Reduction of ICESat systematic geo- 
location errors and the impact on ice sheet elevation change detection. Geophys. Res. Lett., 32, L21S05, doi: 10.1029/2005GL023689.

Magruder, L. A., 2002: Pointing angle and timing verification of the Geoscience Laser Altimeter using a groundbased detection system, CSR-01-03, Center for Space Research, University of Texas at Austin.

Magruder, L. A., C. E. Webb, T. J. Urban, E. C. Silverberg, and B. E. Schutz, 2007: ICESat altimetry data product verification at White Sands Space Harbor. IEEE Trans. Geosci. Remote Sensing, 45, 147-155, doi:10.1109/TG RS.2006.885070.

Martin, C. F., R. H. Thomas, W. B. Krabill, and S. S. Manizade, 2005: ICESat range and mounting bias estimation over precisely-surveyed terrain. Geophys. Res. Lett., 32, L21S07, doi: 10.1029/2005GL023800.

Mitchum, G. T., 1994: Comparison of TOPEX sea surface heights and tide gauge sea levels. J. Geophys. Res., 99, 24541-24554

Mitchum, G. T., 1998: Monitoring the stability of satellite altimeters with tide gauges. J. Atmos. Ocean. Technol., 15, 7210730 .

Myers, N., R. A. Mittermeier, C. G. Mittermeier, G. A. B. Fonseca, and J. Kent, 2000: Biodiversity hotspots for conservation priorities. Nature, 403, 853-858.

Neuenschwander, A. L., R. Gutierrez, B. E. Schutz, and T. J. Urban, 2006: Comparison of Small-footprint and Large-footprint Waveform Lidar for Terrestrial Surface Characterization, IEEE IGARSS Proceedings, August 1 - 5, Denver, CO, 3758-3761, doi: 10.1109/ IGARSS.2006.963.

NOAA, 2006: Hurricane Katrina: A Climatological Perspective, Technical Report 2005-01, October 2005, updated August 2006, http://www.ncdc.noaa.gov/oa/reports/ tech-report-200501z.pdf, last accessed 25 April 2007.

NSIDC (National Snow and Ice Data Center), no date: ICESat/GLAS data at NSIDC, http://nsidc.org/data/icesat, last accessed 25 April 2007.

Padman, L., and H. A. Fricker, 2005: Tides on the Ross Ice Shelf observed with ICESat. Geophys. Res. Lett., 32, L14503, doi: 10.1029/2005GL023214.

Palm, S., W. Hart, D. Hlavka, E. J. Welton, A. Mahesh, and J. Spinhirne, 2002: GLAS atmospheric data products, Geoscience Laser Altimeter System (GLAS) Algorithm Theoretical Basis Document Version 4.2, http:// www.csr.utexas.edu/glas/pdf/glasatmos.atbdv4.2.pdf, last accessed 25 April 2007.

Phillips, H. A, J. R. Ridgeway, J. B. Minster, Y. Donghui, and C. Bently, 1999: Tidal corrections, Geoscience Laser Altimeter System (GLAS) Algorithm Theoretical Basis Document Version 2.0, http://www.csr.utexas. edu/glas/atbd.html, last accessed 25 April 2007.
Rapley, C. G., M. A. J. Guzkowska, W. Cudlip, and I. M. Mason, 1987: An exploratory study of inland water and land altimetry using Seasat data, ESA Report No. 6483/85/NL/BI.

Rim, H. J., and B. E. Schutz, 2002: Precision orbit determination (POD), Geoscience Laser Altimeter System (GLAS) Algorithm Theoretical Basis Document Version 2.2, http://www.csr.utexas.edu/glas/atbd.html, last accessed 25 April 2007.

SCF (GLAS Science Computing Facility), no date: http:// glas-scfweb.gsfc.nasa.gov (web interface for the ICESat Science Team), last accessed 25 April 2007.

Schutz, B. E., 1998: Spaceborne Laser Altimetry: 2001 and Beyond, Book of Extended Abstracts, WEGENER98, H. P. Plag (Ed.), Norwegian Mapping Authority, Honefoss, Norway.

Schutz, B. E., 2002: Laser footprint location (geolocation) and surface profiles, Geoscience Laser Altimeter System (GLAS) Algorithm Theoretical Basis Document Version 3.0, http://www.csr.utexas.edu/glas/pdf/atbd geoloc 10 02.pdf, last accessed 25 April 2007.

Schutz, B. E., 2004: ICESat laser altimetry, presented at the Surface Water Working Group meeting, University of California-Irvine, 23 March.

Schutz, B. E., and T. J. Urban, 2004: ICESat Measurements of Rivers and Lakes, Eos Trans. AGU, 85, Fall Meet. Suppl., Abstract H22C-02.

Schutz, B. E., H. J. Zwally, C. A. Shuman, D. Hancock, and J. P. DiMarzio, 2005: Overview of the ICESat Mission. Geophys. Res. Lett., 32, L21S01, doi: 10.1029/ 2005GL024009.

Sun, X., J. B. Abshire, D. Yi, and H. A. Fricker, 2005: ICESat Receiver Signal Dynamic Range Assessment and Correction of Range Bias due to Saturation, EOS Trans. AGU, 86, Fall Meet. Suppl., Abstract C34A-07.

Tapley, B. D., S. Bettadpur, J. C. Ries, P. F. Thompson, and M. M. Watkins, 2004: GRACE measurements of mass variability in the Earth system. Science, 305, 503-505.

Urban, T. J., and B. E. Schutz, 2005: ICESat sea level comparisons. Geophys. Res. Lett., 32, L23S10, doi: 10.1029/ 2005 GL024306.

WFF (Wallops Flight Facility), NASA Goddard Space Flight Center, no date: Version 5.3 GLAS files, http:// wffglas.wff.nasa.gov/v53 products, last accessed 17 November 2006.

Zwally, H., B. Schutz, W. Abdalati, J. Abshire, C. Bentley, A. Brenner, J. Bufton, J. Dezio, D. Handcock, D. Harding, T. Herring, B. Minster, K. Quinn, S. Palm, J. Spinhirne, and R. Thomas, 2002: ICESat's laser measurements of polar ice, atmosphere, ocean, and land. $J$. Geodyn., 34, 405-445. 